\title{
THE INFLUENCE OF PARTICLE RESIDENCE TIME DISTRIBUTION ON THE REACTIVITY IN FLUIDIZED BED REACTORS
}

\author{
A. B. M. HEESINK, J. KLAUS and W. P. M. VAN SWAAIJ \\ Department of Chemical Engineering, Twente University of Technology, PO Box 217, 7500 AE Enschede, \\ The Netherlands
}

(First received 11 October 1993; accepted in revised form 15 Febrtary 1994)

\begin{abstract}
The influence of particle residence time distribution on the average conversion rate (or reactivity) of particles undergoing a non-catalytic gas solid reaction inside a continuously operated fluidized bed reactor is evaluated. A so-called $\beta$-factor is defined as the ratio of the actual reactivity in the reactor and the reactivity of a batch of particles that react under similar circumstances and that all have a conversion extent equal to the average conversion extent in the reactor. The $\beta$-factor concept is elaborated for shrinking core conversion behaviour. According to Heesink et al. (1993), three extreme types of conversion behaviour are distinguished: core reaction limitation, product-layer ciffusion limitation and grain reaction limitation. For each type of behaviour a mathematical function is derived that expresses $\beta$ as function of average particle conversion, maximum attainable conversion (with regard to pore plugging) and a new-defined expansion factor, which is a measure for the expansion (or shrinking) of the reacting solid during conversion. These functions can be easily incorporated in fluidized bed reactor models.
\end{abstract}

\section{INTRODUCTION}

The average conversion rate (or reactivity) of a mixture of segregated objects (e.g. solid particles, liquid d roplets, gaseous bubbles) that are being converted by a surrounding reactant while having different extents of conversion, is not necessarily equal to the conversion rate of a batch of objects that react under similar conditions and all have a conversion extent equal to the average conversion extent of the mixture [see e.g. Westerterp et al. (1984a)]. This is illustrated by Fig. 1 for reactions which are of the order $0.5,1$ and 2 in the segregated objects. In this paper the term "order" refers to the relationship between the conversion rate of an object and the relative amount of non-converted material $(1-X)$. So, the term order not only reflects intrinsic kinetics. It may, for example, also express the relationship between the surface area available for (heterogeneous) reaction and the extent of conversion (think of shrinking core mechanism). Figure $1 \mathrm{com}-$ pares the conversion rate of a single object with a conversion extent of $70 \%$ (open spheres) with the average conversion rate of a mixture of two objects with conversion extents of 50 and $90 \%$, respectively (closed spheres). Apparently a distribution in conversion extent has a negative impact on reactivity when the order in the objects is smaller than one, i.e when the curves are concave. A positive impact is observed when the order is higher than one, i.e. when the curves are convex. When the order equals one (corresponding with a straight curve), a distribution in conversion extent does not affect the reactivity of a mixture. Note that these conclusions are valid for any type of distribution in conversion extent.

Particles inside batchwise operated bubbling fluidized bed reactors usually are ideally mixed. Con- ditions to be satisfied are small differences in particle size and density (Nienow et al., 1978) and the absence of mechanical barriers like densely packed heat exchanger tubes (Sutherland and Wong, 1964, Sitnai, 1981). If these conditions are satisfied, a continuously operated bubbling fluidized bed reactor can be regarded as a Completely Segregated Stirred Tank Reactor (CSSTR) provided that the average residence time of the particles is long in comparison with the time needed for particle mixing (Yagi and Kunii, 1961; Cranfield, 1978). Although particles are not ideally mixed in the riser section of a circulating fluidized bed reactor (Rhodes et al., 1991), a circulating fluidized bed reactor as a whole can also be regarded as a CSSTR when the incremental particle conversion per pass is relatively small. In that case a large particle recycle ratio is commonly applied, resulting in CSSTR behaviour (Westerterp et al., 1984b). It is therefore obvious that particles entering a continuously operated bubbling or circulating fluidized bed reactor will have different residence times, resulting in particle residence time distribution (particle-RTD). When the fluidized particles participate in some non-catalytic reaction, particle- $R T D$ causcs a distribution in particle conversion extent which affects the reactivity inside a reactor if particle conversion behaviour is not first order in the particles. Examples of fluidized bed processes in which non-catalytic reactions are performed and where particle-RTD may affect reactivity are

- the combustion or gasification of high-ash coal, - the in situ removal of sulphur dioxide with limestone during fluidized bed coal combustion, the roasting of iron sulphide to obtain iron oxide 


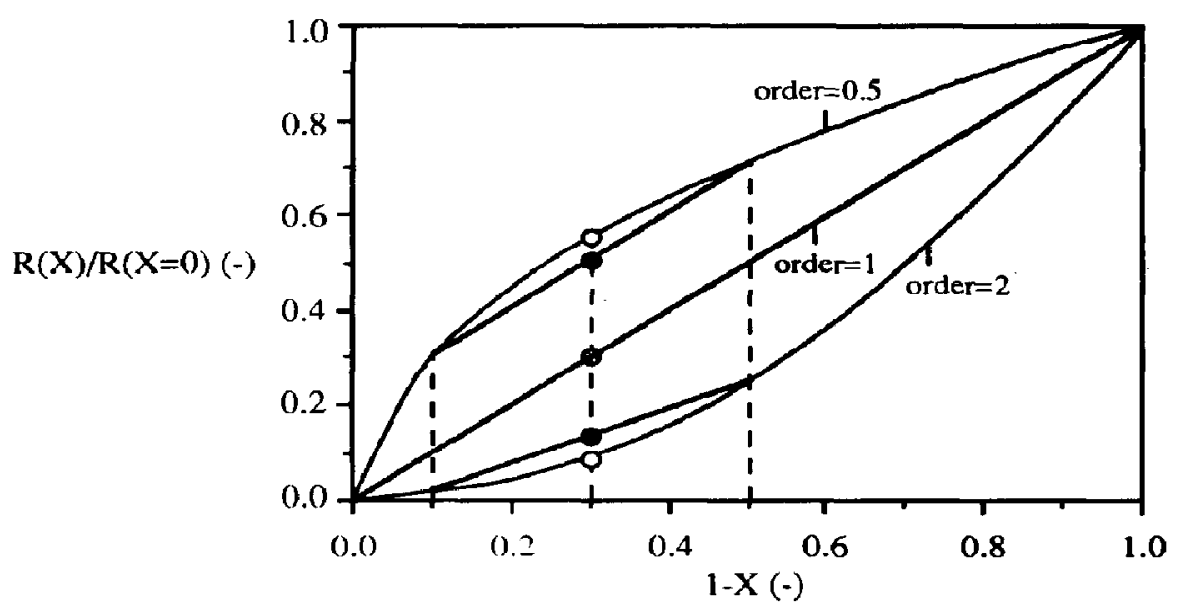

Fig. 1. Normalized rate-vs-concentration curves for reactions of 0.5-, 1- and 2-order in the segregated objects.

and the subsequent reduction of iron oxide to produce iron in the steelworks,

the calcination of limestone in the cement industries,

- the purification of gas streams using porous particles, impregnated with an absorbing liquid (Hogendoorn et al., 1993).

In our group we are developing a process for the regenerative desulphurization of coal gas using limestone and dolomite as regenerable sorbents and (circulating) fluidized bed reactors as gas-solid contactors. We determined particle conversion behaviour during sulphidation and regeneration in a thermogravimetric analyser. It appeared that a modified version of the grain model of Sohn and Szekely (1972) describes our results quite well (Heesink et al., 1993). In this model the porous limestone and dolomite particles are assumed to consist of small impervious spherical grains which react with the surrounding reactant gas according to the shrinking core model first proposed by Yagi and Kunii (1955). Figures 2 and 3 illustrate this concept. Notice that the conversion behaviour of a porous particle as a whole is similar to that of the individual grains provided that no pore diffusion limitation occurs. According to Heesink et al. (1993) three steps are involved in the conversion of a grain (Fig. 3): a grain surface reaction (further denoted as grain reaction) which is not included in the classical shrinking core model, productlayer (or ash-layer) diffusion and a core surface reaction (further denoted as core reaction). Each of these steps may limit the overall conversion rate of a grain or particle. It is for example generally assumed that the rate of the reaction between calcined limestone and sulphur dioxide is governed by product-layer diffusion (Borgwardt and Bruce, 1986). The rate of the reaction between calcined limestone and hydrogen sulphide is most probably governed by some core reaction (Heesink et al., 1993) as is the rate of limestone calcination (Dennis and Hayhurst, 1987). The rate of the regeneration reaction between sulphided dolomite and a mixture of carbon dioxide and steam was found to be governed by a grain reaction (Heesink et al., 1993).

In fluidized bed reactor models, the reactivity of the bed towards a reactant gas is often calculated by inserting the average conversion of the particles in the appropriate equation from the shrinking core model. The influence of particle-RTD on reactivity is then neglected. This is for example done by FaltsiSaravelou and Vasalos (1990) in their model describing the removal of sulphur dioxide from flue gases in a bubbling fluidized bed absorber. A reactor model that does include the effect of particle-RTD on bed reactivity is the so-called D.U.T.-SURE model of Schouten (1988). This model describes the in situ removal of sulphur dioxide with limestone in a bubbling fluidized bed coal combustor. However, the influence of particle-RTD on bed reactivity was not explicitly evaluated. In their book about fluidization engineering, Kunii and Levenspiel (1991) evaluate the influence of particle-RTD on the average outlet conversion of particles but do not derive equations that quantify the effect of particle-RTD on the reactivity of a bed towards a reactant gas (or liquid).

In this paper we will derive easy to use mathematical expressions that quantify the effect of particleRTD on reactivity inside fluidized bed reactors in which the particles meet more or less constant reaction conditions during their stay in the reactor. This is the case when the average particle residence time and the time needed for complete conversion are much longer than the time needed for complete mixing. First, a so-called $\beta$-factor is introduced. This factor is defined as the ratio of the actual reactivity in a continuously operated fluidized bed reactor and the reactivity of a batch of particles that all have a conversion 


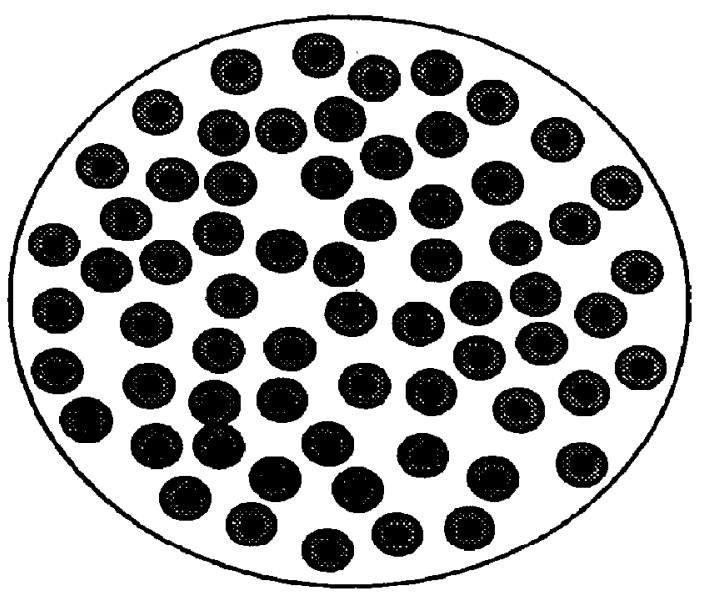

Fig. 2. Representation of a particle according to the grain model of Sohn and Szekely (1972); grains are assumed to be spherical.

extent equal to the average conversion extent in the reactor. The $\beta$-factor concept will first be elaborated for conversion behaviour which is of $n$th order in the particles. The fact that the conversion extent of initially porous particles may he limited by pore blocking, possibly occurring when the grains inside the reacting particle expand during conversion, will be considered. Then, for each type of shrinking core conversion behaviour a mathematical expression will be derived that explicitly gives $\beta$ as function of average particle conversion, maximum attainable conversion (with regard to pore blocking) and a new defined grain expansion factor. Finally, the $\beta$-factor concept will be applied to a circulating fluidized bed absorber in which sulphur dioxide is removed from a flue gas stream by precalcined limestone.

\section{MATHEMATICAL DEFINITION OF THE $\beta$-FACTOR}

The reactivity of particles in a continuously operaled fluidized bed reactor in which an average conversion extent of $\bar{X}_{\text {csstr }}$ is reached, is frequently estimated [e.g. Faltsi-Saravelou and Vasalos (1990)] by putting it equal to the reactivity of a batch of particles that react under similar circumstances and that all have reached a conversion extent of $\bar{X}_{\text {csstr. }}$. This reactivity is then calculated according:

$$
R_{\mathrm{BATCH}}=\left(1-\varepsilon_{\mathrm{O}}\right) N_{\mathrm{o}}\left[\frac{\mathrm{d} X(t)}{\mathrm{d} t}\right]_{X=\bar{x}_{\mathrm{CSSTR}}} .
$$

In this equation $\boldsymbol{R}_{\mathrm{BATCH}}$ represents the reactivity ( $\mathrm{mol} \mathrm{m}_{p}^{-3} \mathrm{~s}^{-1}$ ) of a batch of particles all being converted to the same extent, i.e. $\overline{\boldsymbol{X}}_{\text {Csstr. }}$. The conversion rate $(\mathrm{d} X / \mathrm{d} t)$ is a function of particle conversion $(X)$ and refers to the reaction conditions inside the reactor which are assumed not to vary with time and place. The parameter $\varepsilon_{0}$ represents the initial porosity of the

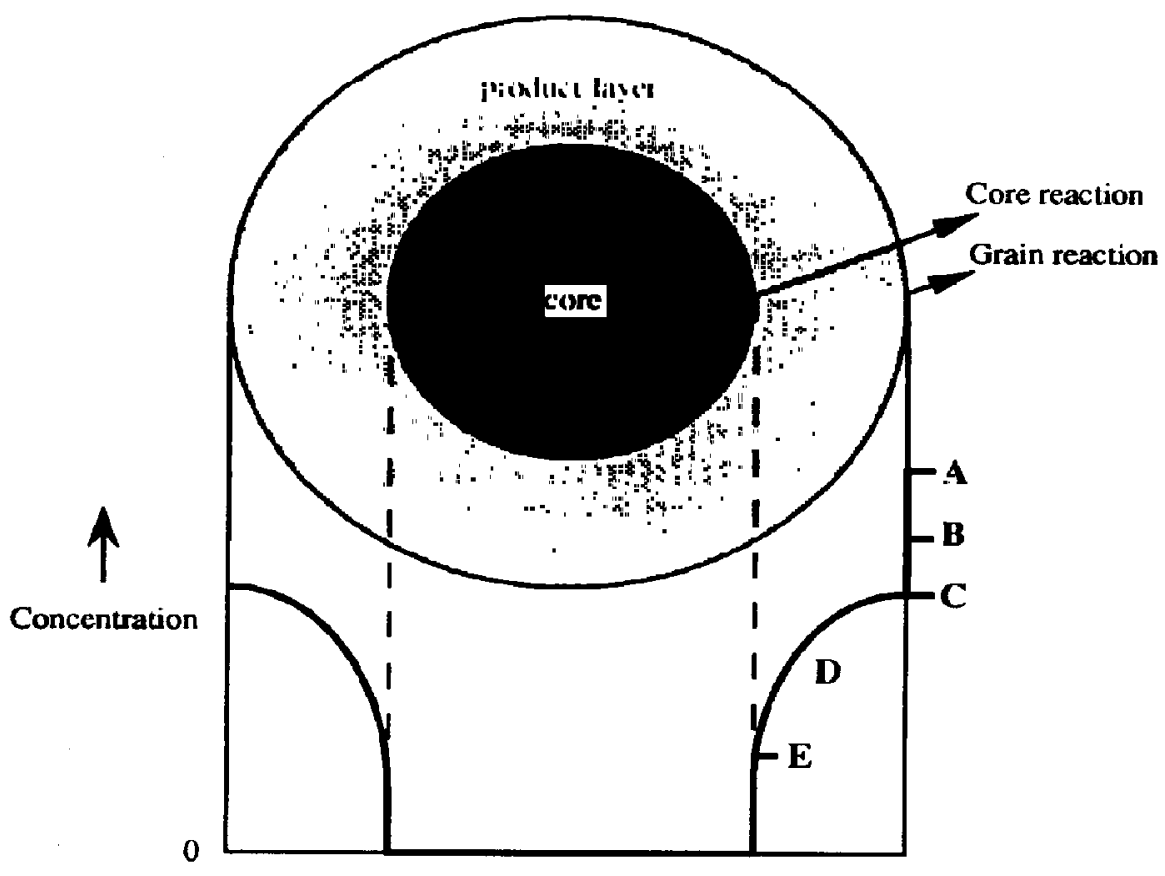

Fig. 3. Illustration of the shrinking core model for a single grain; distinct steps are the grain reaction, product-layer diffusion and the core reaction. $\mathbf{A}=$ volumetric concentration of gaseous reactant at the grain border. $B=$ surface concentration of gascous reactant (according adsorption isotherm). $C=$ surface concentration of (ionic) species produced during grain reaction. $\mathrm{D}=$ produt-layer diffusion of (ionic) species. $\mathrm{E}=$ surface concentration of (ionic) species at core surface. 
particles whereas $N_{0}$ represents the initial concentration of the solid reactant in the non-porous grains, given by

$$
N_{\mathrm{o}}=\frac{P}{V_{\text {sol, reac }}}
$$

where $P$ represents the purity of the initial material and $V_{\text {sol, reac }}$ the molar volume of the solid reactant.

Due to particle-RTD, the particles inside a fluidized bed reactor have different extents of conversion. The actual or average reactivity of the ideally mixed particles inside a fluidized bed reactor can be calculated from

$$
R_{\operatorname{CssTR}}=\left(1-\varepsilon_{\mathrm{o}}\right) N_{\mathrm{o}} \int_{t=0}^{1=\infty}\left\{E_{\operatorname{CssTR}}(t)\left[\frac{\mathrm{d} X(t)}{\mathrm{d} t}\right] \mathrm{d} t\right\}
$$

$E_{\operatorname{csstR}}(t)$ represents the residence time distribution function for a CSSTR, which is given by

$$
E_{\operatorname{CsSTR}}(t)=\frac{1}{\tau} \exp \left(-\frac{t}{\tau}\right)
$$

The parameter $\tau$ represents the average residence time of the particles in the bed and can be calculated according

$$
\tau=\stackrel{M_{\mathrm{bed}}}{\Phi_{m}}
$$

with $M_{\text {bed }}$ and $\Phi_{m}$ representing the bed mass and the mass flow rate of the particles, respectively. Combination of eqs (1), (3) and (4) yields

$R_{\text {CSSTR }}$

$$
\begin{aligned}
& =\frac{\int_{t=0}^{t=\infty}\left\{\frac{1}{\tau} \exp \left(-\frac{t}{\tau}\right)\left[\frac{\mathrm{d} X(t)}{\mathrm{d} t}\right] \mathrm{d} t\right\}_{R_{\mathrm{BATCH}}}}{\left[\frac{\mathrm{d} X(t)}{\mathrm{d} t}\right]_{X=\bar{x}_{\mathrm{CSBT}}}} \\
& =\beta R_{\mathrm{BATCH}} .
\end{aligned}
$$

Since $\boldsymbol{R}_{\text {Batch }}$ represents the reactivity of a batch of particles that all have a conversion extent of $\bar{X}_{\text {csstr }}$ and that react under similar circumstances as the particles inside a fluidized bed reactor, the factor $\beta$ solely expresses the influence of particle-RTD on the reactivity in a fluidized bed reactor. After partial integration of the numerator, eq. (6) can be rewritten as

$$
\beta=\frac{\int_{t=0}^{t=\infty}\left[\frac{1}{\tau^{2}} \exp \left(-\frac{t}{\tau}\right) X(t) \mathrm{d} t\right]-\frac{X(t=0)}{\tau}}{\left[\frac{\mathrm{d} X(t)}{\mathrm{d} t}\right]_{X=\bar{x}_{\mathrm{CSSTR}}}}
$$

The average conversion of the particles leaving a fluidized bed reactor can be calculated according to

$$
\bar{X}_{\text {Csstr }}=\int_{t=0}^{t=\infty}\left[\frac{1}{\tau} \exp \left(-\frac{t}{\tau}\right) X(t) \mathrm{d} t\right] .
$$

When the conversion of the particles at the reactor inlet $[X(t=0)]$ is fixed at 0 , combination of eqs (7) and $(8)$ yields

$$
\beta=\frac{\bar{X}_{\text {CSSTR }}}{\tau\left[\frac{\mathrm{d} X(t)}{\mathrm{d} t}\right]_{X=\bar{X}_{\mathrm{cssT}}}}
$$

It appears that the functions $[\mathrm{d} X(t) / \mathrm{d} t]$ and $X(t)$ for batch-type conversion are needed to calculate the value of $\beta$. Below, these functions will be derived for the three extreme cases of core reaction limitation, product-layer diffusion limitation and grain reaction limitation. Before doing so we will first illustrate the $\beta$-factor concept for conversion behaviour that is of $n$th order in the particles.

\subsection{Conversion behaviour of the nth order type}

Although most gas-solid reactions can be best described with the shrinking core model, conversion behaviour that is of $n$th order in the particles is sometimes observed. Some dissociation reactions, for example the pyrolysis of wood (Thurner and Mann, 1981), the thermal degradation of synthetic polymers (Sawagushi et al., 1990) and the thermal decomposition of zinc and magnesium oxalates (Danforth and Dix, 1971) appear to be of first order in the dissociating solid. When particle conversion behaviour is of the $n$th order type, the following applies:

$$
\begin{array}{ll}
\frac{\mathrm{d} X}{\mathrm{~d} t}=K_{r}(1-X)^{n} & \text { for } X<X_{\max } \\
\frac{\mathrm{d} X}{\mathrm{~d} t}=0 & \text { for } X=X_{\max } .
\end{array}
$$

The maximum attainable extent of conversion, $X_{\max }$, may either be one or smaller than one when pore blocking occurs. If pore blocking occurs during the homogeneous conversion of an initially porous particle, $X_{\max }$ can be calculated from

$$
X_{\max }=\frac{\varepsilon_{0}}{\left(1-\varepsilon_{0}\right) N_{0}\left(V_{\text {sol, prod }}-V_{\text {sol, reac }}\right)} \text { but } X_{\max } \leqslant 1
$$

Integration of eq. (10) yields the function $X(t)$ which can be inserted into eq. (8) to determine $\bar{X}_{\text {Css TR }}$ which on its turn can be inserted into eq. (9) to find $\beta$. Table 1 gives the equations that are obtained for conversion behaviour which is of the order zero, half, one and two in the particles. In Fig. $4, \beta$ is plotted against $\bar{X}_{\text {Csst }}$ for a $X_{\max }$ value of one. The results agree with the findings of Fig. 1: at orders smaller than one, particle-RTD has a negative impact on reactivity $(\beta<1)$ whereas particle-RTD has a positive impact on reactivity at orders greater than one $(\beta>1)$. The influence of particle-RTD is most pronounced at a high average conversion degree.

Figure 4 shows that $\beta$ tends to the value of one at low $\bar{X}_{\operatorname{csst} R}$ values in all considered cases. This can be explained as follows. According to eq. (6), $\beta$ is defined as the ratio of the average reactivity and the reactivity 
Table 1. Summary of $\beta$-equations for 0 -, 0.5-, 1 - and 2-order particle conversion behaviour; $s=K$, $\tau$

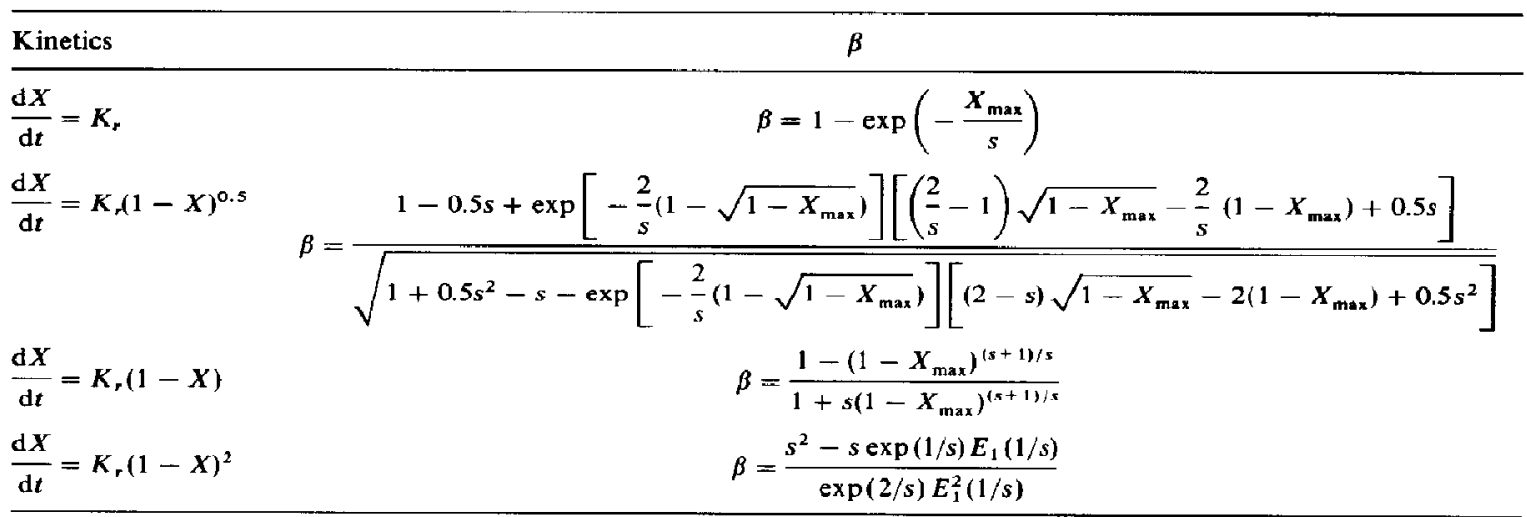
$E_{1}(x)=\int_{x}^{\infty x} \frac{\exp (-y)}{y} \mathrm{~d} y$ to be taken from e.g. Abramowitz and Stegun (1972).

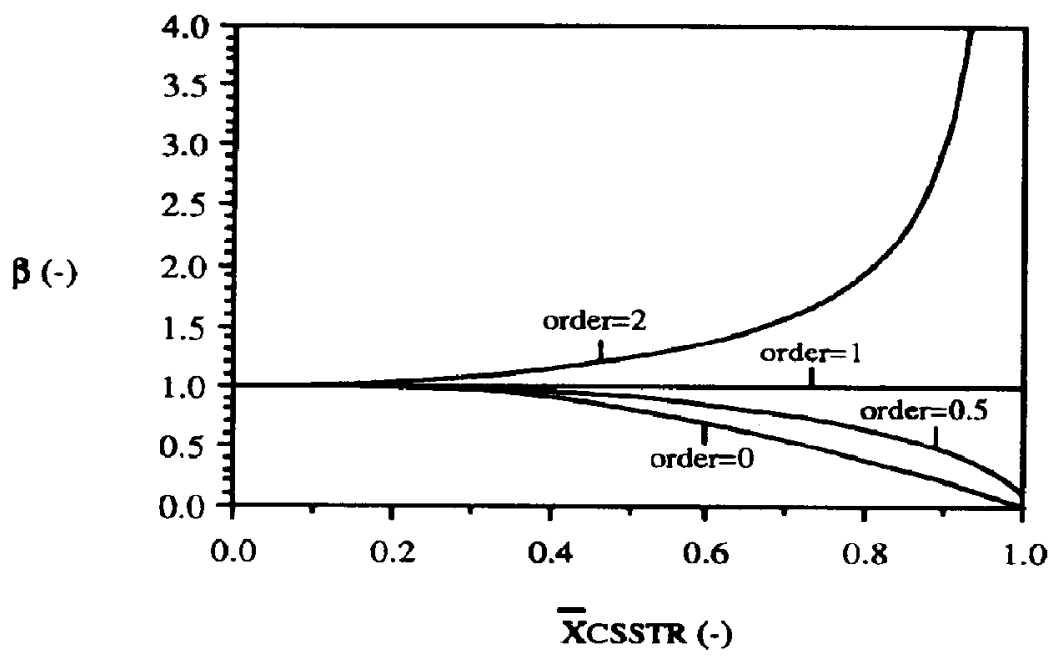

Fig. 4. $\beta$-vs-conversion curves for reactions of $0-, 0.5-, 1$ - and 2 -order in the segregated objects.

at average conversion. Thus,

$$
\beta=\frac{(\overline{\mathrm{d} X}}{\left(\frac{\mathrm{d} X}{\mathrm{~d} t}\right)_{X=\bar{x}_{\mathrm{cSsT}}}}=\frac{[\overline{f(X)}]}{[f(\bar{X})]}=1 \text { for } \bar{X}_{\operatorname{cssTR}} \downarrow 0 .
$$

In general, the average value of a continuous function $f(X)$ on the closed interval $[0, y]$ [denoted as $\overline{f(X)}$ in eq. (12)] becomes equal to $f(\bar{X})$ [where $\bar{X}$ represents the average value of $X$ in the considered interval (here to be regarded as $\left.\left.\bar{X}_{\text {cSstr }}\right)\right]$ when $y$ approaches the value of zero. For this to be true, $f(X)$ should be defined for all values of $X$ in the closed interval $[0, y]$. Here this implies that the function $(\mathrm{d} X / \mathrm{d} t)$ should be defined for all $X$ in the closed interval $[0, y]$. In practice this condition is always obeyed. Thus at low values of $\bar{X}_{\text {Csstr }}, \beta$ adapts the value of one.
Now that the $\beta$-factor concept is somewhat illustrated we will further concentrate on shrinking core conversion behaviour.

\section{ELABORATION FOR SHRINKING CORE CONVERSION BEHAVIOUR}

The kinetics of most gas-solid reactions can be described with the shrinking core model, often in conjunction with a grain model. Some examples are the calcination of limestone [core reaction limitation; Dennis and Hayhurst (1987)], the sulphation of calcined limestone [product-layer diffusion; Borgwardt and Bruce (1986)], the regeneration of sulphided limestone with mixtures of carbon dioxide and steam [grain reaction limitation; Heesink et al. (1993)], the reduction of magnetite to wüstite and subsequently to iron by carbon monoxide [core reaction limitation; Park and Levenspiel (1975)] and, finally, the sulphida- 
tion of zinc-titanium oxides [both core reaction and product-layer diffusion play a role; Lew et al. (1992)]. In this section the functions $X(t)$ and $[\mathrm{d} X(t) / \mathrm{d} t]$, needed to calculate $\beta$, will be derived for each extreme of shrinking core conversion behaviour. Intermediate cases, in which more than one of the steps denoted in Fig. 3 affect the conversion rate of a grain, will not be considered.

\subsection{Core reaction limitation}

In case of core reaction limitation, the conversion rate of a single grain with initial radius $\boldsymbol{R}_{\mathrm{D}}$ can be calculated from

$$
\frac{4}{3} \pi R_{0}^{3} N_{\mathrm{o}} \frac{\mathrm{d} X}{\mathrm{~d} t}=4 \pi R_{\mathrm{c}}^{2} k_{\mathrm{c}} C_{\mathrm{c}} .
$$

$\boldsymbol{R}_{\boldsymbol{c}}$ represents the radius of the unconverted core which can be calculated from

$$
R_{c}=(1-X)^{1 / 3} R_{0} .
$$

The parameter $k_{\mathrm{c}}$ represents the kinetic constant of the core reaction, which is assumed to be first order in the adsorbed gaseous reactant. $C_{r}$ represents the concentration of the gaseous reactant (i.e. some ionic species; $\mathrm{E}$ in Fig. 3) at the core surface which, in case of core reaction limitation, equals the concentration at the surface of the grain, $C_{g}$ (C in Fig. 3). In its turn $C_{g}$ is somehow related to the volumetric concentration of the gaseous reactant surrounding the grain (A in Fig. 3).

Combination of eqs. (13) and (14) yields

$$
\begin{array}{ll}
\frac{\mathrm{d} X}{\mathrm{~d} t}=3 K_{c}(1-X)^{2 / 3} & \text { for } X<X_{\max } \\
\frac{\mathrm{d} X}{\mathrm{~d} t}=0 & \text { for } X=X_{\max } .
\end{array}
$$

Apparently, core reaction limitation corresponds to the $n$th order conversion behaviour, $n$ being $2 / 3 . K_{c}$ can be regarded as the overali reaction rate constant in case of core reaction limitation, and is given by

$$
K_{c}=\frac{k_{c} C_{q}}{R_{0} N_{0}}
$$

As the reacting particles move through the bed, the concentration of the gaseous reactant surrounding the particles, and thus the values of $C_{g}$ and $K_{c}$, may vary. Here we neglect such variation: $C_{g}$ and $K_{c}$ refer to the average surface concentration in the bed. The error caused by this assumption will be small when the following conditions are fulfilled:

$$
\tau \gg \tau_{\text {mix }}, \quad \tau_{\text {conv }} \gg \tau_{\text {mix }} \text {. }
$$

Here $\tau_{\mathrm{mix}}$ represents the time needed for complete mixing of the particles which usually is less than $1 \mathrm{~min}$ [see e.g. Rowe (1973)], whereas $\tau_{\text {conv }}$ represents the time needed for complete conversion of a particle. In most practical cases eq. (17) is obeyed.
When eq. (15) is integrated, we obtain

$$
\begin{array}{ll}
X(t)=1-\left(1-K_{c} t\right)^{3} & \text { for } t \leqslant t\left(X_{\max }\right) \\
X(t)=X_{\max } & \text { for } t>t\left(X_{\max }\right) .
\end{array}
$$

Equations (8) and (18) can now be combined to derive an expression for $\bar{X}_{\text {Csstr: }}$

$$
\begin{aligned}
\bar{X}_{\mathrm{CSSTR}}= & \exp \left(\frac{\left(1-X_{\max }\right)^{1 / 3}-1}{s}\right)\left[6 s^{2}\left(1-X_{\max }\right)^{1 / 3}\right. \\
& \left.-3 s\left(1-X_{\max }\right)^{2 / 3}-6 s^{3}\right]+6 s^{3}+3 s-6 s^{2}
\end{aligned}
$$

with $s=K_{c} \tau$. Thus, $\bar{X}_{\mathrm{CssTR}}$ is a function of $X_{\max }$ and $s$. Combination of eqs (9) and (15) results in

$$
\beta=\frac{\bar{X}_{\text {CSSTR }}}{3 s\left(1-\bar{X}_{\text {CsstR }}\right)^{2 / 3}} \text {. }
$$

Obviously, $\beta$ is a function of $\bar{X}_{\text {CSstr }}$ and $s$, which on its turn is related to $X_{\max }$ and $\bar{X}_{\mathrm{CssiR}}$ through eq. (19). It is therefore possible to express $\beta$ as function of $\bar{X}_{\text {Csstr }}$ and $X_{\max }$. As eq. (19) cannot be inverted analytically, this can only be done numerically.

\subsection{Product-layer diffusion limitation}

In the case of product-layer diffusion limitation, the conversion rate can be calculated from

$$
\frac{4}{3} \pi R_{0}^{3} N_{0} \frac{\mathrm{d} X}{\mathrm{~d} t}=4 \pi R^{2} D_{s}\left(\frac{\mathrm{d} C}{\mathrm{~d} r}\right)_{r=R}
$$

$D_{s}$ represents the diffusivity of the product-layer and $r$ the distance between the centre of the grain and the radial position $R$ in the product-layer. Since no reaction takes place in the product-layer, the transport rate of gaseous reactant through the product-layer does not vary with radius. Equation (21) can therefore be rewritten as

$$
\frac{\mathrm{d} X}{\mathrm{~d} t}=\frac{3 D_{s}}{N_{0} R_{0}^{3}} \frac{\left(C_{g}-C_{c}\right)}{\left(\frac{1}{R_{c}}-\frac{1}{R_{g}}\right)}
$$

The radius of the partly converted grain can be calculated from

$$
R_{g}=R_{0}(K X+1)^{1 / 3}
$$

where $K$ represents the expansion factor, defined as

$$
K=N_{\mathrm{O}}\left(\boldsymbol{V}_{\text {sol, prod }}-V_{\text {sol, reac }}\right) \text {. }
$$

Combining eqs (2) and (24) yields

$$
K=P\left(\frac{V_{\text {sol, prod }}}{V_{\text {sol, reac }}}-1\right)
$$

Obviously, $K$ has a minimum value of $-1(P=1$ and $V_{\text {sol, prod }}=0$ ). However, in that case no product-layer is being formed and product-layer diffusion limitation cannot occur. In Table 2, $K$-values are given for a number of gas-solid reactions involving pure solid reactants $(P=1)$.

When product-layer diffusion controls the rate of conversion, $C_{c}$ will be much smaller than $C_{g}$. This, 
Table 2. Values of expansion factor $(\boldsymbol{K})$ for some reversible gas-solid reactions: pure solids assumed

\begin{tabular}{|c|c|c|c|}
\hline & Reaction & $K_{\text {left to } r i g h t}$ & $K_{\text {right to left }}^{\dagger}$ \\
\hline $\begin{array}{l}\mathrm{CaCO} \\
\mathrm{CaCO}_{3} \cdot \mathrm{MgCO}_{3} \\
\mathrm{CaCO} \cdot \mathrm{MgO}_{3} \\
\mathrm{CaCO} \cdot \mathrm{MgCO}_{3} \\
\mathrm{CaO} \cdot \mathrm{MgO}_{2}+\mathrm{H}_{2} \mathrm{~S} \\
\mathrm{CaO}+\mathrm{H}_{2} \mathrm{~S} \\
2 \mathrm{CaO}+2 \mathrm{SO}_{2}+\mathrm{O}_{2} \\
\mathrm{CaCO} \cdot \mathrm{MgO}_{3}+\mathrm{H}_{2} \mathrm{~S} \\
4 \mathrm{FeS}+7 \mathrm{O}_{2} \\
\mathrm{FeO}+\mathrm{CO} \\
4 \mathrm{Fe}+3 \mathrm{O}_{2} \\
\mathrm{ZnO}+\mathrm{H}_{2} \mathrm{~S} \\
\mathrm{MnO}+\mathrm{H}_{2} \mathrm{~S}\end{array}$ & $\begin{array}{l}\Leftrightarrow \mathrm{CaO}+\mathrm{CO}_{2} \\
\Leftrightarrow \mathrm{CaCO}-\mathrm{MgO}+\mathrm{CO}_{2} \\
\Leftrightarrow \mathrm{CaO} \cdot \mathrm{MgO}+\mathrm{CO}_{2} \\
\Leftrightarrow \mathrm{CaO} \cdot \mathrm{MgO}+2 \mathrm{CO}_{2} \\
\Leftrightarrow \mathrm{CaS} \cdot \mathrm{MgO}+\mathrm{H}_{2} \mathrm{O} \\
\Leftrightarrow \mathrm{CaS}+\mathrm{H}_{2} \mathrm{O} \\
\Leftrightarrow 2 \mathrm{CaSO} \\
\Leftrightarrow \mathrm{CaS} \cdot \mathrm{MgO}^{\prime} \mathrm{CO}_{2} \quad \mathrm{H}_{2} \mathrm{O} \\
\Leftrightarrow 2 \mathrm{Fe}_{2} \mathrm{O}_{3}+4 \mathrm{SO}_{2} \\
\Leftrightarrow \mathrm{Fe}+\mathrm{CO}_{2} \\
\Leftrightarrow 2 \mathrm{Fe} \mathrm{O}_{3} \\
\Leftrightarrow \mathrm{ZnS}+\mathrm{H}_{2} \mathrm{O} \\
\Leftrightarrow \mathrm{MnS}+\mathrm{H}_{2} \mathrm{O}\end{array}$ & $\begin{array}{r}-0.55 \\
-0.26 \\
-0.42 \\
-0.57 \\
0.38 \\
0.66 \\
1.75 \\
-0.19 \\
-0.39 \\
-0.41 \\
1.13 \\
0.66 \\
1.03\end{array}$ & $\begin{array}{r}1.21 \\
0.35 \\
0.72 \\
1.33 \\
-0.28 \\
-0.40 \\
-0.64 \\
0.24 \\
0.64 \\
0.69 \\
-0.53 \\
-0.40 \\
-0.51\end{array}$ \\
\hline
\end{tabular}

$' K_{\text {right to left }}=\frac{-K_{\text {left to right }}}{K_{\text {left to right }}+1}$.

Note: Data derived from molar volumes as given by Weast (1983).

together with substitution of $R_{c}$ and $R_{e}$ according to eqs (14) and (23) into eq. (22), yields

$$
\begin{aligned}
& \frac{\mathrm{d} X}{\mathrm{~d} t}=\frac{3 K_{p}}{\left(\frac{1}{1-X}\right)^{1 / 3}-\left(\frac{1}{1+K X}\right)^{1 / 3}} \\
& \text { for } X<X_{\max } \text { and } K>-1 \\
& \frac{\mathrm{d} X}{\mathrm{~d} t}=0 \text { for } X=X_{\max } .
\end{aligned}
$$

It is obvious that conversion behaviour generally is not of the $n$th order type in case of product-layer diffusion limitation. Only for extremely high $K$ values, conversion behaviour is of the $n$th order type, $n$ being $1 / 3$.

The overall reaction are constant in case of product-layer diffusion limitation, $K_{p}$, is defined as

$$
K_{p}=\frac{D_{s} C_{g}}{N_{0} R_{0}^{2}}
$$

The reaction rate constants $K_{c}$ and $K_{p}$ appear to be inter-related according to

$$
K_{p}=\frac{K_{c}}{\psi} \quad \text { with } \psi=\frac{k_{c} R_{0}}{D_{s}} \text {. }
$$

Integration of eq. (26) yields

$$
\begin{array}{r}
t(X)=\frac{1}{2 K_{p}}\left\{1-(1-X)^{2 / 3}+\frac{1}{K}\left[1-(K X+1)^{2 / 3}\right]\right\} \\
\text { for } X<X_{\max }, \quad K \neq 0 \quad(29) \\
t(X)=\frac{1}{2 K_{p}}\left[1-(1-X)^{2 / 3}-\frac{2}{3} X\right] \\
\text { for } X<X_{\max }, \quad K=0 .
\end{array}
$$

It is not possible to invert eq. (29) in order to obtain the function $X(t)$, which is needed to derive an expression for $\bar{X}_{\text {CSsTR }}$ and subsequently $\beta$. Furthermore, eq. (26) predicts an infinitely high initial conversion rate (when no product-layer has been built-up yet). Since this is not realistic, a certain core reaction is assumed to limit the initial conversion rate. It is therefore necessary to derive an expression in which both core reaction and product-layer diffusion are considered. This is done below.

3.2.1. General expression for core reaction and product-layer diffusion. When some core reaction as well as product-layer diffusion affect the conversion rate, eqs (13) and (22) both apply. These equations can be combined by eliminating the parameters $C_{c}$. Subsequent substitution of $R_{c}$ and $R_{g}$ according to eqs (14) and (23), and introduction of $K_{c}$ and $\psi$, as defined by eqs (16) and (28), yields the following general expression:

$$
\begin{aligned}
& \frac{\mathrm{d} X}{\mathrm{~d} t}=\frac{3 K_{c}}{\frac{1}{(1-X)^{2 / 3}}+\psi\left[\frac{1}{(1-X)^{1 / 3}}-\frac{1}{(1+K X)^{1 / 3}}\right]} \\
& \text { for } X<X_{\max } \\
& \frac{d X}{d t}=0 \text { for } X=X_{\max }
\end{aligned}
$$

This expression is valid for both core reaction limitation and product-layer diffusion limitation as well as for intermediate cases: at large values of $\psi\left(k_{c} R_{0} \gg D_{s}\right)$ eq. (26) is obtained whereas eq. (15) is obtained at $\psi$-values much smaller than one $\left(k_{c} R_{0} \ll D_{s}\right)$. The value of $\psi$ thus determines which mechanism is rate controlling:

$\psi \ll 1$ : core reaction limitation

$\psi \gg 1$ : product-layer diffusion limitation .

At very low conversions $(X \approx 0)$, eq. $(30)$ is similar to eq. (15). Thus the initial conversion rate is prevented from becoming infinitely high. Notice that eq. (30) also resembles eq. (15) when $K$ equals -1 . In 
that case no product-layer is being formed and core reaction limitation is the only possible mechanism left.

The time needed to obtain a certain conversion extent is obtained by integration of eq. (30):

$$
\begin{aligned}
& t(X)=\frac{1-(1-X)^{1 / 3}}{K_{c}} \\
& +\frac{\psi}{2 K_{c}}\left\{1-(1-X)^{2 / 3}+\frac{1}{K}\left[1-(K X+1)^{2 / 3}\right]\right\} \\
& \quad \text { for } X<X_{\max }, \quad K \neq 0 \\
& t(X)=\frac{1-(1-X)^{1 / 3}}{K_{c}}+\frac{\psi}{2 K_{c}}\left[1-(1-X)^{2 / 3}-\frac{2}{3} X\right] \\
& \quad \text { for } X<X_{\max }, \quad K=0 .
\end{aligned}
$$

Only when $\psi$ equals zero (core reaction limitation) eq. (32) can be inverted analytically into the function $X(t)$ [namely eq. (17)]. When product-layer diffusion plays a role $(\psi>0), X$ has to be calculated numerically at given values of $t$. For this we apply the Newton-Corden method. $\bar{X}_{\text {CSsTR }}$ can subsequently be calculated by application of eq. (8). Integration is performed numerically according to the Romberg method. Once $\bar{X}_{\text {Csstr }}$ has been calculated, $\beta$ can be calculated using eqs (9) and (29). The described numerical procedure has been successfully checked by comparing numerically calculated values of $\bar{X}_{\text {CSSTR }}$ and $\beta$ for the case of core reaction limitation $(\psi=0)$ with values obtained with the analytical eqs (19) and (20).

From eqs (30) and (32) it follows that $\bar{X}_{\text {Csstr }}$ and $\beta$ are functions of $s, X_{\max }, K$ and $\psi$. If product-layer diffusion fully governs the conversion rate $(\psi \gg 1)$, the value of $\psi$ is not of interest as can be seen from eqs (25) and (28). Then both $\bar{X}_{\mathrm{cssTR}}$ and $\beta$ are functions of $s, X_{\max }$ and $K$ only. As a consequence, $s$ can be expressed as function of $\bar{X}_{\mathrm{CssTR}}, X_{\max }$ and $K$, implying that $\beta$ can be expressed as function of $\bar{X}_{\mathrm{CSSTR}}, K$ and $X_{\max }$ through eq. (9).

\subsection{Grain reaction limitation}

Equations (30) and (32) are valid when core reaction and product-layer diffusion are the only steps in the conversion mechanism. However, it is quite well possible that a gaseous reactant, before passing the product-layer by solid-state diffusion, is first converted into some ionic species at the outer surface of the grain according to a grain reaction (Heesink et al., 1993). Therefore, we consider grain reaction limitation as a third possible reaction mechanism.

If a grain reaction controls the conversion rate, the following applies:

$$
\frac{4}{3} \pi R_{0}^{3} N_{0} \frac{\mathrm{d} X}{\mathrm{~d} t}=4 \pi R_{a}^{2} k_{a} C_{a}^{\prime} .
$$

Here $C_{g}^{\prime}$ represents the concentration of the adsorbed gaseous reactant at the grain surface (denoted as $B$ in Fig. 3). Combination of eqs (23) and (33) together with some re-arrangement yields

$$
\begin{array}{ll}
\frac{\mathrm{d} X}{\mathrm{~d} t}=3 K_{g}(K X+1)^{2 / 3} & \text { for } X<X_{\max } \\
\frac{\mathrm{d} X}{\mathrm{~d} t}=0 & \text { for } X=X_{\max } .
\end{array}
$$

$K_{g}$ represents the overall reaction rate constant in case of grain reaction limitation:

$$
K_{o}=\frac{k_{g} C_{g}^{\prime}}{R_{0} N_{0}} .
$$

In general, grain reaction limitation does not correspond to the $n$th order conversion behaviour. Only when $K$ equals 0 or -1 , conversion behaviour is of the $n$th order type, $n$ being 0 and $2 / 3$, respectively. In the latter case no product-layer is being formed (the solid reactant is converted into gas only). The terms core reaction and grain reaction then refer to the same surface reaction.

It is not possible to couple eqs (30) and (34) by putting $C_{g}$ equal to $C_{g}^{\prime}$. The symbol $C_{q}$ as used in eq. (30) (by means of $K_{c}$ ) refers to the concentration of the (ionic) species, which is formed at the grain surface, diffuses through the product-layer and subsequently reacts at the core surface ( $\mathrm{C}$ in Fig. 3 ). The concentration $C_{g}^{\prime}$ in eq. (33) (through $K_{\theta}$ ) refers to the concentration of the adsorbed gascous rcactant at the grain surface (B in Fig. 3). In general, it is not possible to combine the three steps of grain reaction, productlaycr diffusion and core reaction, without violating the assumption of the shrinking core model that $C_{g}^{\prime}$ is constant during conversion. However, this violation is avoided when only the extreme cases of core reaction limitation, product-layer diffusion limitation and grain reaction limitation are considered as is done in this paper.

Integration of eq. (34) yields:

$$
\begin{array}{ll}
X(t)=\frac{\left(K K_{g} t+1\right)^{3}-1}{K} & \text { for } t \leqslant t\left(X_{\max }\right) \text { and } K \neq 0 \\
X(t)=3 K_{g} t & \text { for } t \leqslant t\left(X_{\max }\right) \text { and } K=0 \\
X(t)=X_{\max } & \text { for } t>t\left(X_{\max }\right) .
\end{array}
$$

When eq. (36) is inserted into eq. (8), the following expression is obtained after partial integration:

$$
\begin{aligned}
\bar{X}_{\text {CSSTR }}= & 3 s+6 s^{2} K+6 s^{3} K^{2} \\
& -\exp \left[\frac{1-\left(K X_{\max }+1\right)^{1 / 3}}{s K}\right] \\
& \times\left[3 s\left(K X_{\max }+1\right)^{2 / 3}+6 s^{2} K\right. \\
& \left.\times\left(K X_{\max }+1\right)^{1 / 3}+6 s^{3} K^{2}\right] \text { for } K \neq 0 \\
\bar{X}_{\text {CSSTR }}= & 3 s\left[1-\exp \left(-\frac{X_{\max }}{3 s}\right)\right] \text { for } K=0
\end{aligned}
$$

with $s$ representing $K_{\theta} \tau$. Combination of eqs (9) and (34) yields the following expression for $\beta$ :

$$
\beta=\frac{\bar{X}_{\mathrm{CSSTR}}}{3 s\left(K \bar{X}_{\mathrm{CSSTR}}+1\right)^{2 / 3}} .
$$


When $K$ equals -1 the terms grain reaction and core reaction refer to the same reaction, and eq. (38) is similar to eq. (20), as is to be expected.

From eq. (37) it can he concluded that $\bar{X}_{\text {Csstr }}$ is a function of $s, K$ and $X_{\max }$. Thus at fixed values of $K$ and $X_{\max }, s$ can be expressed as function of $\bar{X}_{\text {CSsTR }}$. Furthermore, $\beta$ is a function of $\bar{X}_{\text {csstr }}$ and $s$. This implies that, as in the case of product-layer diffusion limitation, $\beta$ can be expressed as function of $\bar{X}_{\text {CSSTR }}$, $K$ and $X_{\max }$.

\section{RESULTS AND DISCUSSION}

In the previous section it was shown that it is possible to express $\beta$ as function of $\bar{X}_{\mathrm{CSSTR}}, X_{\max }$ and, when product-layer diffusion or a grain reaction are rate determining, the expansion factor $K$. This can only be done numerically by calculating $\beta$ at different values of $\bar{X}_{C S s T r}, X_{\max }$ and $K$, and then fitting the results. In this way fit-functions will be derived for each type of shrinking core conversion behaviour.

\subsection{Core reaction limitation}

In Fig. $5, \beta$ is plotted as function of particle utilization, here defined as $\bar{X}_{\text {Csstr }} / X_{\max }$, for different values of $X_{\max }$. As to be expected, $\beta$ starts from a value of one at zero particle utilization. As long as particle utilization is kept below some $40 \%$, the influence of particle-RTD on reactivity may be neglected. However, when particle utilization is further raised, $\beta$ drops below one as to be expected for $n$th order conversion behaviour with $n<1(n=2 / 3)$. See also Fig. 7 which shows the concave nature of the ratevs-concentration curve for core reaction limitation. The influence of particle-RTD on reactivity is most pronounced at low $X_{\max }$ values. This can be easily understood: the sudden drop in reactivity due to pore plugging increases at decreasing values of $\boldsymbol{X}_{\max }$ -

The solid lines in Fig. 5 were calculated according to the fit-function:

$$
\begin{aligned}
& \beta=1-\exp \left[-4.2\left(1-\frac{\bar{X}_{\text {CSstR }}}{X_{\max }}\right)^{q}\right] \\
& q=1.5-0.9 \exp \left[-2\left(1-X_{\max }\right)^{0.85}\right] .
\end{aligned}
$$

As shown in Fig. 6, the correlation between the exact and the approached $\beta$-values appears to be quite good $\left(R^{2}=0.9965\right)$. Nevertheless, at predicted $\beta$-values less than about 0.2 , it is recommended to make use of eqs (19) and (20) for more accurate calculations. In that case $s$ must first be determined by insertion of the (known) values of $\bar{X}_{\mathrm{rsstr}}$ and $X_{\max }$ into eq. (19) and subsequent application of the "trial-and-error" method. When $s$ is determined, $\beta$ can be found through application of eq. (20).

\subsection{Product-layer diffusion limitation}

Besides $\bar{X}_{\text {CSstr }}$ and $X_{\max }$, the expansion factor $K$ now also influences the value of $\beta$. When $K \leqslant 0$, the grains either shrink or do not change in size implying that pore plugging cannot occur: calculations need then only be done for $X_{\max }=1$. When $K \geqslant 0$ grains do expand and pore plugging can occur. In that case calculations have to be done for different values of $X_{\max }$. All calculations, discussed below, were performed at a fixed $\psi$-value of $10^{6}$. Calculations performed at higher $\psi$-values confirmed that productlayer diffusion is the limiting mechanism at $\psi=10^{6}$.

Figures 8-10 show $\beta$ as function of particle utilization at different values of $X_{\max }$ and $K$-values of 1,2 and 10 , respectively. It seems that $\beta$ starts from a value of $1.5-1.6$ at low values of particle utilization. This is in conflict with expectations: a $\beta$-value of one is to be expected at zero particle utilization. However, by performing some additional calculations at extremely low particle utilization it was found that $\beta$ does approach the value of one as particle utilization tends to

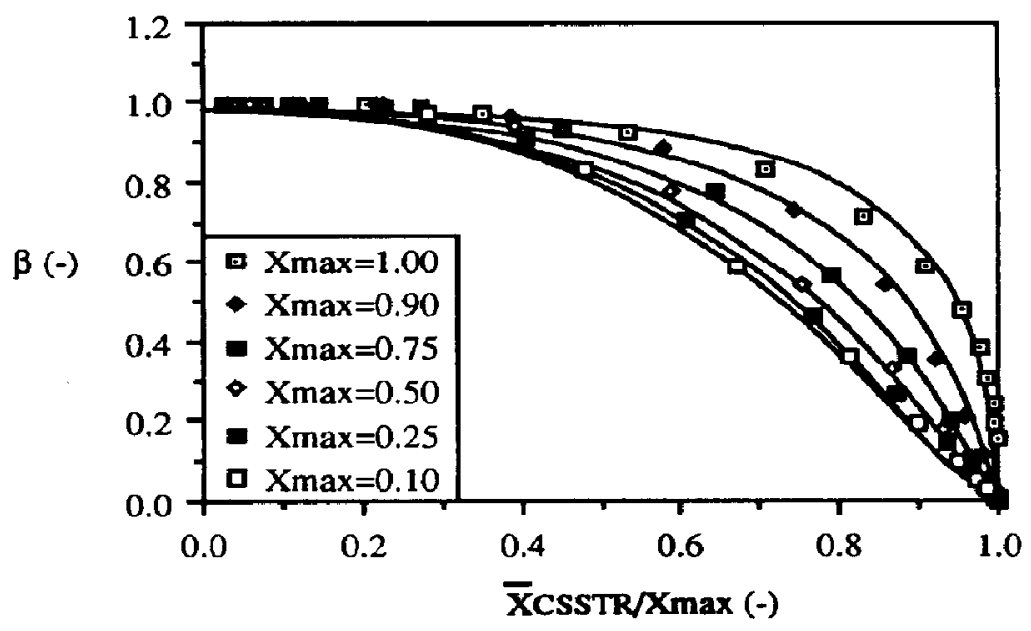

Fig. 5. Plot of $\beta$ against particle utilization for core reaction limitation at different values of $X_{\max }$. Data points are exact solutions; solid lines represent approximate solutions according to eq. (39). 


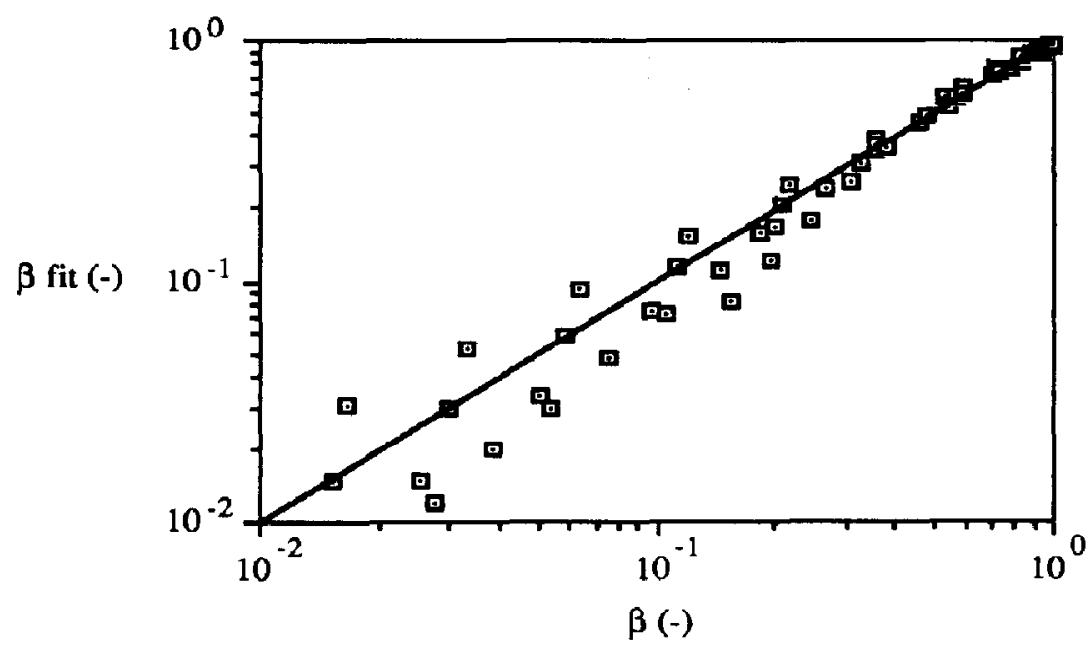

Fig. 6. Parity plot for core reaction limitation [eq. (39), $R^{2}=0.9965$ ].

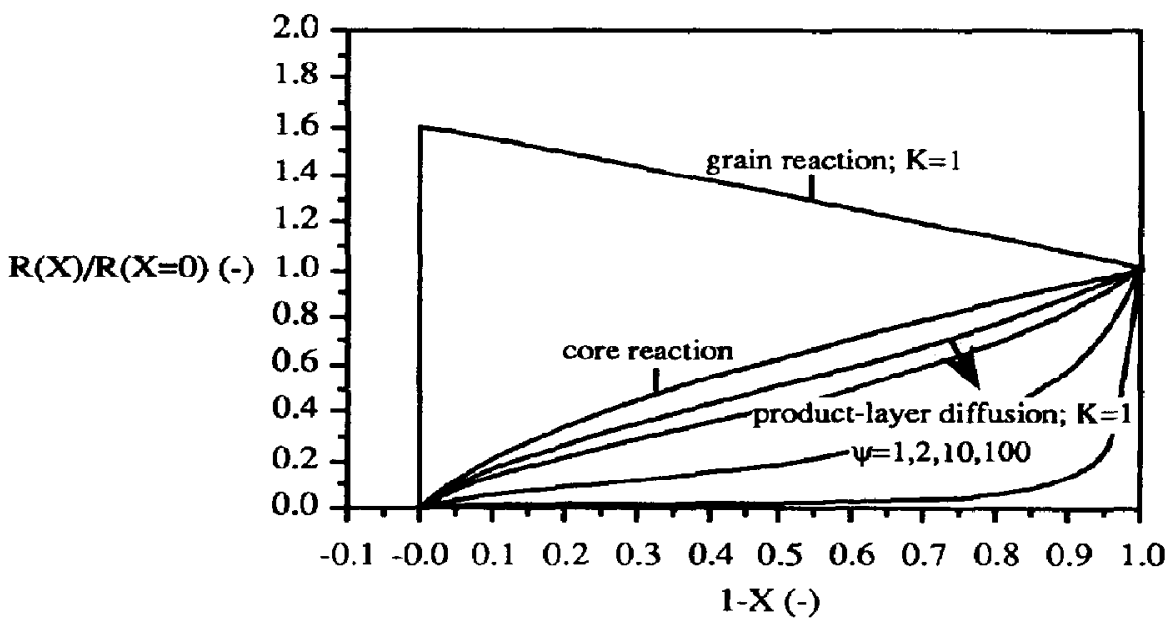

Fig. 7. Normalized rate-vs-concentration curves for core reaction limitation, product-layer diffusion limitation (at $K=1$ and different $\psi$-values) and grain reaction limitation (at $K=1$ ).

zero. The lowest $\beta$-value that could be calculated without numerical problems was 1.3 . Without these problems, a $\beta$-value of one would most certainly be obtained at zero particle utilization. The reason for the numerical difficulties is illustrated by Fig. 7 in which rate-vs-concentration curves are given at relatively low values of $\psi$. At a $\psi$-value of $10^{6}$, one may expect an extremely sharp drop in reaction rate as particle utilization starts to deviate from zero. This sharp drop is the cause for the observed numerical problems.

It is interesting to examine why $\beta$ adopts the value of 1.5-1.6 at low values of particle utilization. In the appendix it is shown mathematically that $\beta$ approaches the value of $\pi / 2$ at low $\bar{X}_{\text {CSstr }}$ values in the unrealistic case that product-layer diffusion is rate determining even during the initial stage of conversion. This surprising result confirms the correctness of the numerical calculations but seems to be in conflict with the demand formulated by eq. (12). However, the condition for eq. (12) to be valid, stating the $(\mathrm{d} X / \mathrm{d} t)$ should be defined for all values of $X$ in the closed interval $[0, y]$ with $y \downarrow 0$, is not satisfied. As stated earlier, $(\mathrm{d} X / \mathrm{d} t)$ becomes infinite at $X=0$ [see eq. (26)]. The $\beta$-value being $\pi / 2$ at zero particle utilization is thus not in conflict with theory. We may thus conclude that particle-RTD has a positive impact on reactivity at low and moderate values of particle utilization and a negative impact at high values of particle utilization when product-layer diffusion is the 


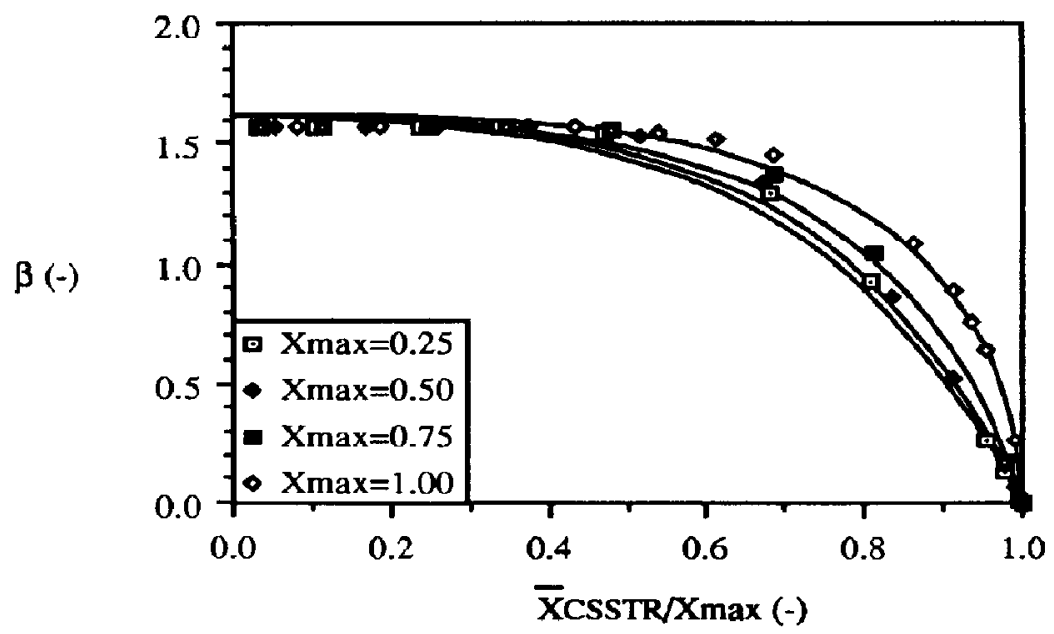

Fig. 8. Plot of $\beta$ against particle utilization for product-layer diffusion limitation at different values of $X_{\max }$ and $K=1$. Data points are exact solutions; solid lines represent approximate solutions according to eq. (40).

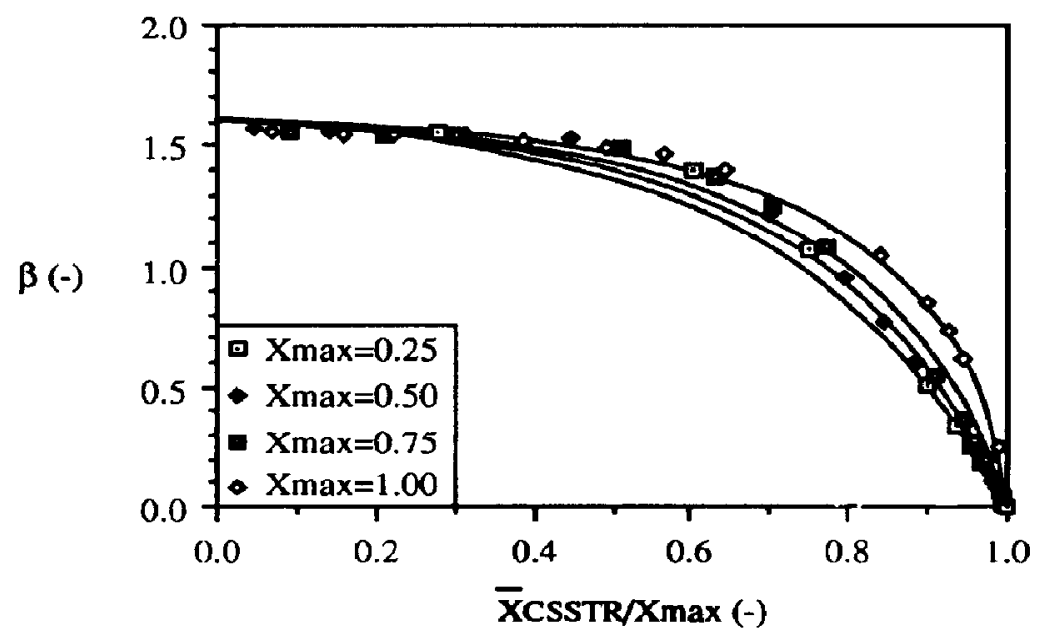

Fig. 9. Plot of $\beta$ against particle utilization for product-layer diffusion limitation at different values of $X_{\max }$ and $K=2$. Data points are exact solutions; solid lines represent approximate solutions according to eq. $(40)$.

governing mechanism. The negative impact at high values of particle utilization can be explained by closely examining the nature of the rate-vs-concentration curves at high particle utilization degrees (see Fig. 7). When doing so one finds that the shape of the rate-vs-concentration curves changes from convex into concave as particle conversion approaches the value of 1.

Comparison of Figs $8-10$ illustrates that the $\beta$ vs-utilization curve declines less rapidly at lower $K$ values. This trend is confirmed by Fig. 11 in which $\beta$-vs-utilization curves are given for $K=0$ and $K=-0.5$, respectively. Calculations performed at $K$-values of $-0.9,-0.99$ and -0.999 indicated somewhat deviating behaviour. However, when regarding realistic $K$-values (see e.g. Table 2), one must conclude that the case of $K$ being less than -0.9 is somewhat academic.

The solid lines in Figs 8-11 were obtained using the following fit-function:

$$
\begin{aligned}
& \beta=1.65\left\{1-\exp \left[-\left(2+\frac{4.5}{K+1}\right)\left(1-\frac{\bar{X}_{\text {CSSTR }}}{X_{\max }}\right)^{q}\right]\right\} \\
& q=0.7+0.55\{1-\exp [(0.7 \log K-1.4) \\
& \left.\left.\times\left(1-X_{\max }\right)\right]\right\} \text { for } K>0 \\
& q=0.7 \quad \text { for } K \leqslant 0 \text {. }
\end{aligned}
$$




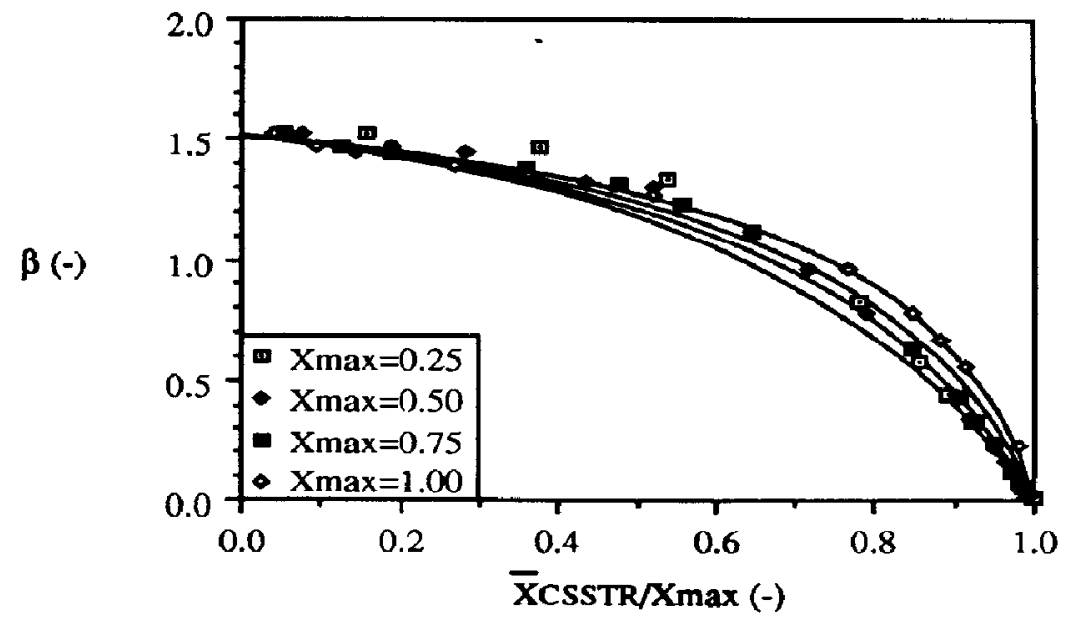

Fig. 10. Plot of $\beta$ against particle utilization for product-layer diffusion limitation at different values of $X_{\max }$ and $K=10$. Data points are exact solutions; solid lines represent approximate solutions according to eq. (40).

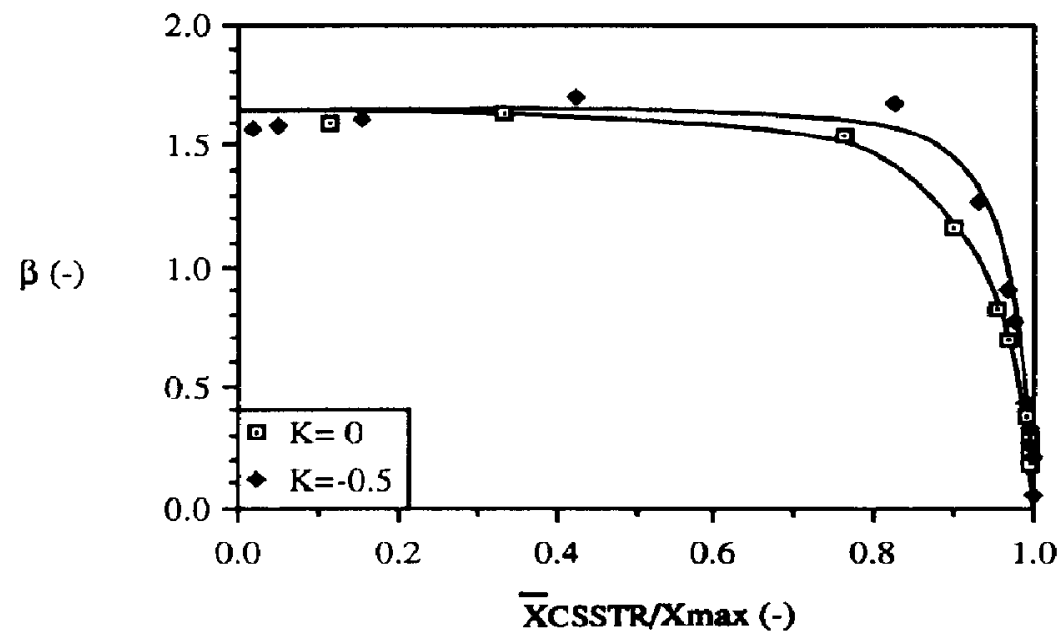

Fig. 11. Plot of $\beta$ against particle utilization for product-layer diffusion limitation at $K=0$ and $K=-0.5$. Data points are exact solutions; solid lines represent approximate solutions according to eq. (40).

As shown in Fig. 12, this formula performs quite well $\left(R^{2}=0.9926\right)$. Note that the obtained fit-function may be erroneous at $K<-0.5$.

\subsection{Grain reaction limitation}

Figures 13-15 show $\beta$ as function of particle utilization at different $X_{\max }$ values for $K=1,2$ and 10 , respectively. It appears that both $X_{\max }$ and $K$ do not affect the $\beta$-vs-utilization behaviour very much. As to be expected, $\beta$ starts from a value of one at zero particle utilization and decreases as particle utilization is increased. This is the consequence of the concave rate-vs-concentration behaviour in case of grain reaction limitation, especially when conversion is almost complete (see Fig. 7). Things are a little different when $K \leqslant 0$. As can be seen from Fig. $16, \beta$ is somewhat higher at lower $K$-values.

The solid lines in Figs 13-16 were calculated according to the following fit-function:

$$
\begin{array}{r}
\beta=1.3\left(1-\frac{\bar{X}_{\text {CSSTR }}}{X_{\max }}\right)^{1.12-0.5 /(K+1.6)} \\
\text { if } \beta \leqslant 1 \text { else } \beta=1 .
\end{array}
$$

As shown in Fig. 17, reasonable fits are obtained with this function $\left(R^{2}=0.9934\right)$, especially when $K \geqslant 0$. 


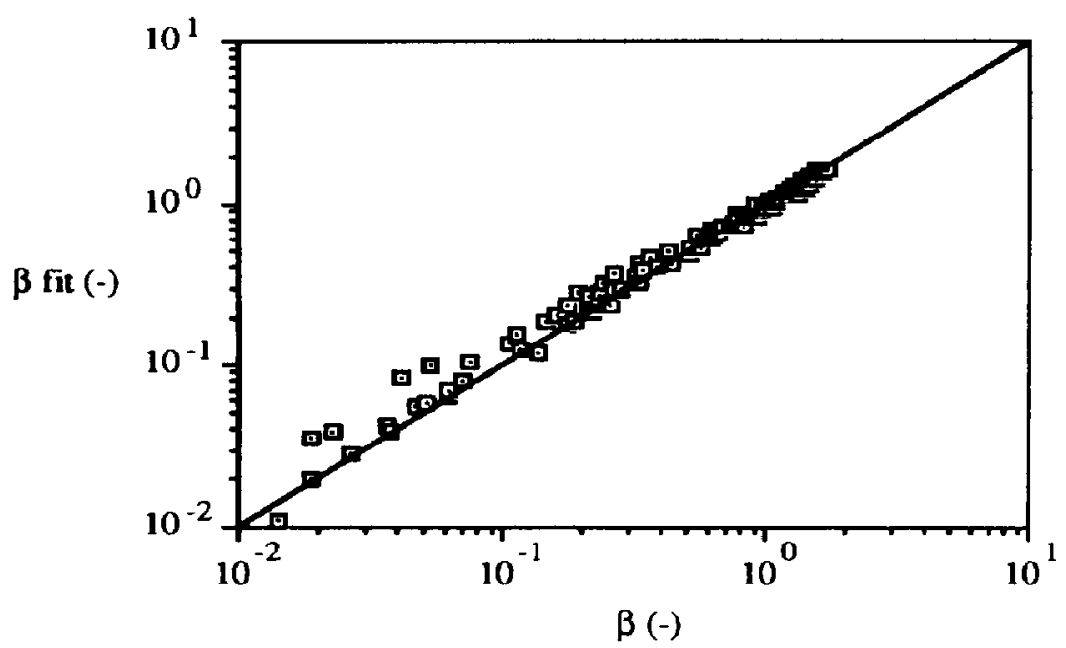

Fig. 12. Parity plot for product-layer diffusion limitation [eq. (40), $\left.R^{2}=0.9926\right] ; K$-values ranging from -0.5 to 10 .

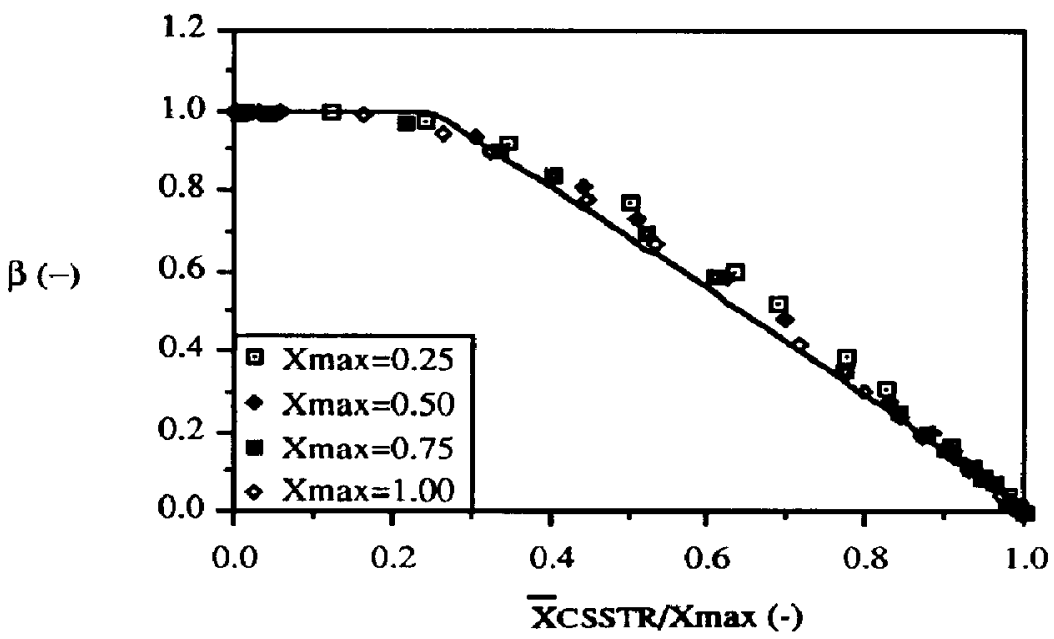

Fig. 13. Plot of $\beta$ against particle utilization for grain reaction limitation at different values of $X_{\max }$ and $K=1$. Data points are exact solutions; solid lines represent approximate solutions according to eq. (41).

However, when $K<0$ and eq. (41) yields $\beta$-values of 0.1 or less, eqs (37) and (38) should be applied. In that case $s$ must first be determined by insertion of the (known) values of $\bar{X}_{\text {csstR }}, X_{\max }$ and $K$ into eq. (37) and subsequent application of the "trial-and-error" method. Note that eq. (41) is also applicable to reactions that are of zeroth order in the particles. In that case a $K$-value of 0 should be inserted .

\subsection{The role of mass transfer}

The derived fit-functions are valid when the conversion rate of the particles is not affected by mass transfer of the gaseous reactant. Below, we will shortly examine how mass transfer phenomena may affect the interference between particle-RTD and reactivity. In fluidized bed reactors three mass transfer resistances can be distinguished:

- between bubble and emulsion phase (in bubbling fluidized beds),

- between gas bulk and particle surface (external), —inside the particles (internal).

In bubbling fluidized bed reactors, particles are practically only present in the emulsion phase. Therefore, the resistance between bubble and emulsion phase will have no influence on the value of $\beta$. Although the concentration of the gaseous reactant in 


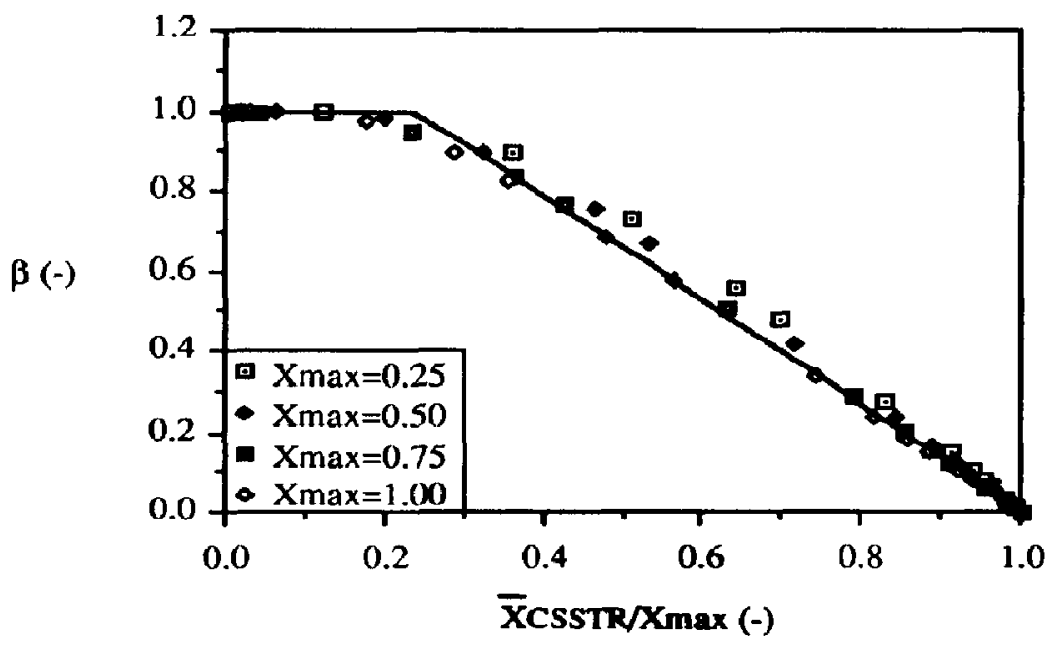

Fig. 14. Plot of $\beta$ against particle utilization for grain reaction limitation at different values of $X_{\max }$ and $K=2$. Data points are exact solutions; solid lines represent approximate solutions according to eq. (41).

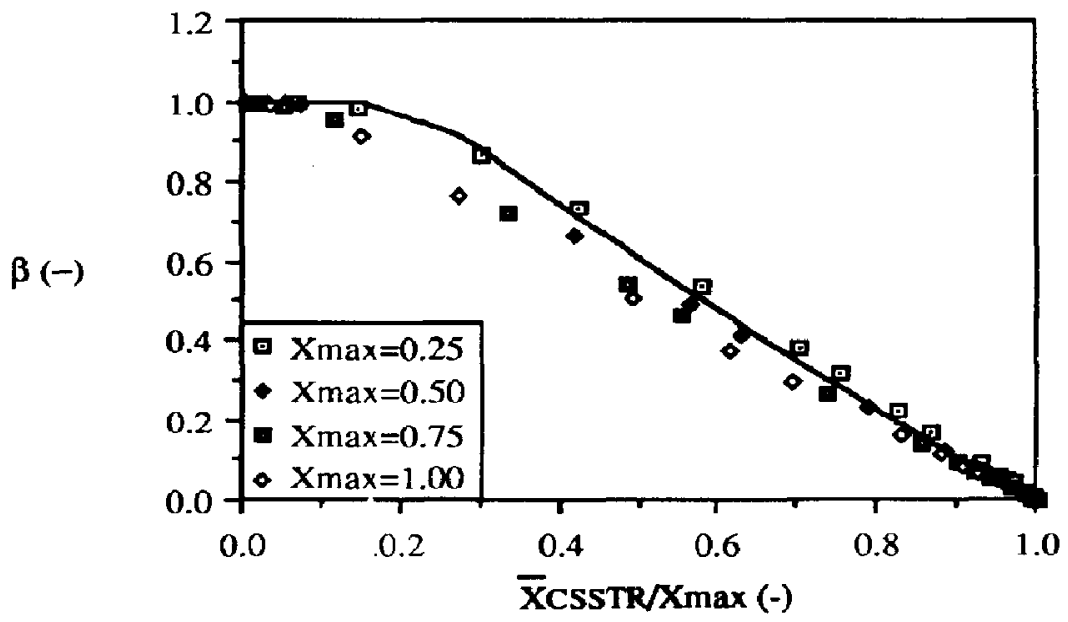

Fig. 15. Plot of $\beta$ against particle utilization for grain reaction limitation at different values of $X_{\max }$ and $K=10$. Data points are exact solutions; solid lines represent approximate solutions according to eq. (41).

the emulsion phase will be lowered by this resistance, this only affects the (average) value of the reaction rate constants $K_{c}$ or $K_{g}$. The derived relationship between $\beta$ on the one hand and $\bar{X}_{\text {Csstr }}, X_{\max }$ and $K$ on the other hand will not be affected. The two remaining resistances may play a role in both bubbling and circulating fluidized bed reactors, especially when fast reactions occur in relatively large particles. Two extremes can be evaluated relatively casily:

- external mass transport limitation,

- internal mass transfer limitation (for porous particles).
In the unlikely case that external mass transfer fully governs the conversion rate of a particle during all stages of conversion, reaction only takes place at the outer surface of the particle and conversion behaviour is similar to the behaviour in the case of grain reaction limitation (the whole particle is then to be regarded as a grain). In that situation $\beta$ can be calculated by use of eq. (41). If the conversion rate of a porous particle is fully governed by internal mass transport during all stages of conversion, reaction only takes place at the surface of a shrinking core consisting of unconverted material. This core is surrounded by a shell of fully converted material. The rate of diffusion of the gas- 


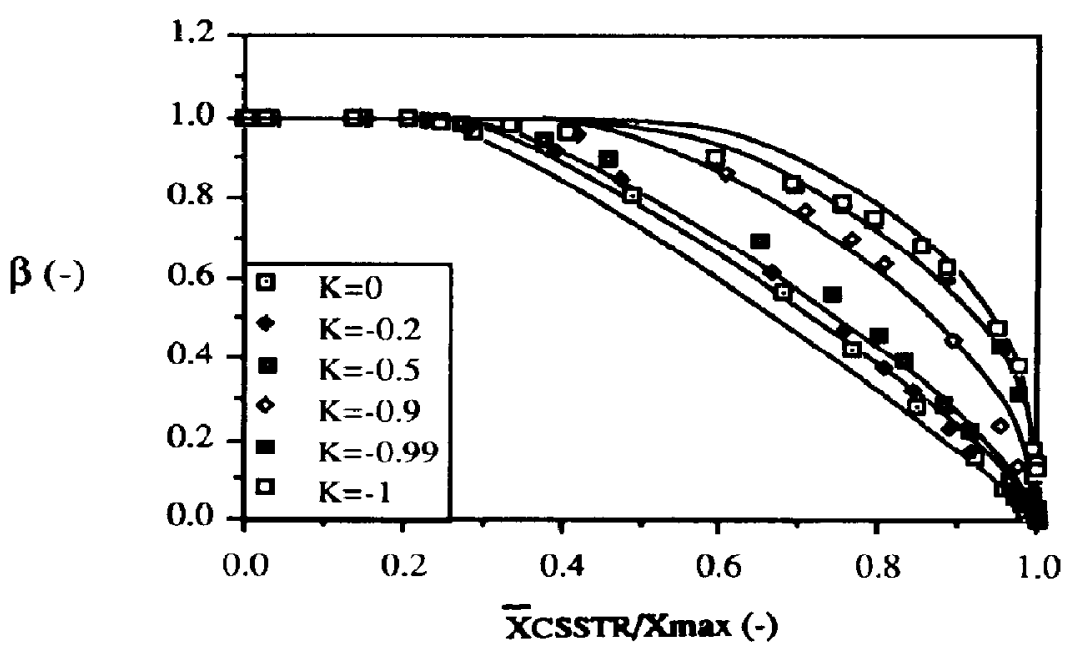

Fig. 16. Plot of $\beta$ against particle utilization for grain reaction limitation at $K=0 ; K=-0.2, K=-0.5$. $K=-0.9, K=-0.99$ and $K=-1$. Data points are exact solutions; solid lines represent approximate solutions according to eq. (41).

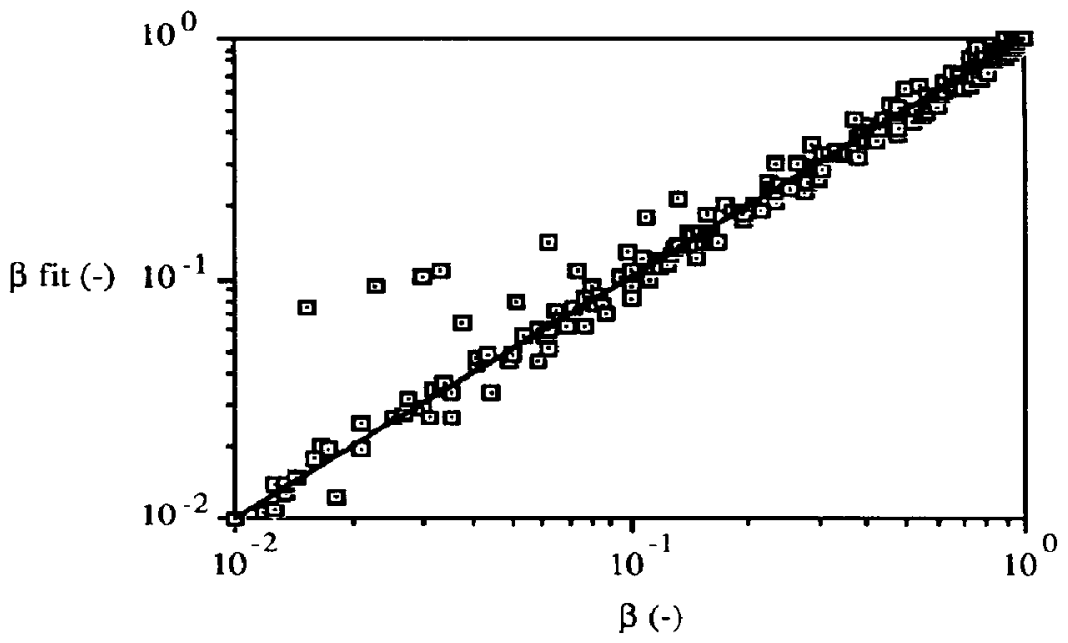

Fig. 17. Parity plot for grain reaction limitation [eq. (41), $R^{2}=0.9934$ ].

eous reactant through this shell (to be regarded as a product-layer) is then limiting. It is obvious that the obtained conversion behaviour can then be described by assuming that product-layer diffusion is limiting (again the whole particle is regarded as a grain). Thus, $\beta$ can be calculated by applying eq. (40). Assuming that the porous particle does not expand during conversion, a $K$-value of 0 should be inserted. When both kinetics and mass transfer affect the conversion rate of a particle, $\beta$ cannot easily be determined.

\subsection{Application of the $\beta$-factor concept in fluidized bed} reactor modelling

The derived fit-functions (39), (40) and (41) can be easily incorporated in fluidized bed reactor models.
For the purpose of illustration, the influence of particle-RTD on the sulphur dioxide capture in a circulating fluidized bed reactor containing precalcined limestone particles will be quantified.

Sulphur dioxide is captured by precalcined limestone according to the following reaction:

$$
\mathrm{CaO}+\mathrm{SO}_{2}+1 / 2 \mathrm{O}_{2} \rightarrow \mathrm{CaSO}_{4}
$$

with $K=1.75$ if the $\mathrm{CaO}$ is pure (see Table 2).

It is generally assumed that the rate of this reaction is controlled by product-layer diffusion (Borgwardt and Bruce, 1986). The concentration of adsorbed $\mathrm{SO}_{2}$ (or the ionic species that migrates through the productlayer) at the grain surface is assumed to be linearly 
dependent on the volumetric concentration of $\mathrm{SO}_{2}$. This is consistent with the results of Borgwardt and Bruce (1986) and Simons et al. (1987), who found that the sulphation reaction is first order in $\mathrm{SO}_{2}$.

We will perform calculations for a bed temperature of $700^{\circ} \mathrm{C}$. The diffusivity of $\mathrm{SO}_{2}$ through the $\mathrm{CaSO}_{4}$ product-layer $\left(D_{\mathrm{s}}\right)$ at $700^{\circ} \mathrm{C}$ is taken from Heesink et al. (1993): $2.6 \times 10^{-13} \mathrm{~m}^{2} \mathrm{~s}^{-1}$. The volumetric firstorder reaction rate constant inside a limestone particle can be calculated as function of particle conversion from

$$
k(X)=\frac{3 D_{s}\left(1-\varepsilon_{n}\right)}{R_{0}^{2}} \frac{1}{\left(\frac{1}{1-X}\right)^{1 / 3}-\left(\frac{1}{1+K X}\right)^{1 / 3}}
$$

The first-order reaction rate constant in the riser section of the reactor can be corrected for the influences of particle-RTD and porosity according:

$$
k_{\text {bed }}=\beta\left(1-\varepsilon_{\text {bed }}\right) k\left(X=\bar{X}_{\text {CSSTR }}\right) .
$$

In eq. (42) the following realistic values are inserted: $D_{s}=2.6 \times 10^{-13} \mathrm{~m}^{2} \mathrm{~s}^{-1}, \varepsilon_{0}-0.5$ and $R_{0}-10^{-7} \mathrm{~m}$. The latter value refers to the size of the grains inside the calcined limestone particles and corresponds with a specific surface area of about $10 \mathrm{~m}^{2} \mathrm{~g}^{-1}$. Putting $K=1.75$ and $\bar{X}_{\text {csstR }}=0.475$, eq. (42) yields a value of $92 \mathrm{~s}^{-1}$ for $k\left(X=\bar{X}_{\text {CSsTR }}\right)$. The value of $X_{\max }$ can be calculated according to eq. (11) and amounts to about 0.5 . Thus, a $\bar{X}_{\text {Csstr }}$ value of 0.475 corresponds with $95 \%$ particle utilization. Putting $\varepsilon_{\text {bed }}=0.98$, eq. (43) yields a $k_{\text {bed }}$ value of $1.8 \mathrm{~s}^{-1}$ when no correction is made for the influence of particle-RTD on reactivity $(\beta=1)$. The $\beta$-value needed to correct for the influence of particle-RTD on reactivity, can be calculated using eq. (39). A value of 0.3 is obtained. The value of $k_{\text {ned }}$ corrected for particle-RTD thus amounts to $0.6 \mathrm{~s}^{-1}$.

Before calculating the capture of $\mathrm{SO}_{2}$, we will first examine whether external and/or internal mass transfer limitation may occur and affect the calculated value of $\beta$. First, we will concentrate on external mass transfer limitation. The relative concentration gradient around a reacting particle with conversion extent $X$ can be calculated according to

$$
\frac{C_{\mathrm{SO}_{2, \text { bulk }}}-C_{\mathrm{SO}_{2 . s}}}{C_{\mathrm{SO}_{2} . \mathrm{s}}}=\frac{k(X) d_{p}^{2}}{6 \mathrm{Sh} D_{\mathrm{SO}_{2} \cdot \mathrm{N}_{2}}} .
$$

Although $k(X)$ is higher at lower conversion extent, we here use the value of $k\left(X=\bar{X}_{\text {CssTR }}\right)$ which amounts to $92 \mathrm{~s}^{-1}$. The diffusivity of $\mathrm{SO}_{2}$ in $\mathrm{N}_{2}$ $\left(D_{\mathrm{SO}_{2}-\mathrm{N}_{2}}\right)$ at $700^{\circ} \mathrm{C}$ and $1 \mathrm{~atm}$ amounts to $10^{-4}$ $\mathrm{m}^{2} \mathrm{~s}^{-1}$. If a particle diameter $\left(d_{p}\right)$ of $10^{-4} \mathrm{~m}$ is chosen and a conservative Sherwood number $(S h)$ of 0.1 is inserted, a relatively small concentration gradient of $1.5 \times 10^{-2}$ is calculated. It is obvious that the gradient will be greater for particles having a lower conversion extent than $\bar{X}_{\text {csstr. }}$. However, as we only want to illustrate the $\beta$-factor concept, we will neglect the influence of external mass transfer limitation on $\beta$. Whether or not internal mass transport limitation occurs can be checked by calculating the value of the Thiele modulus:

$$
\phi-\frac{d_{p}}{6} \sqrt{\frac{k(X)}{D_{\mathrm{SO}_{2} \text { eff }}}} .
$$

The effective diffusivity of $\mathrm{SO}_{2}$ in the particle $\left(D_{\mathrm{SO}_{2} \text {-eff }}\right)$ is estimated to be $10^{-5} \mathrm{~m}^{2} \mathrm{~s}^{-1}$. When we again insert $k\left(X=\bar{X}_{\mathrm{CssTR}}\right)=92 \mathrm{~s}^{-1}$ and $d_{p}=10^{-4} \mathrm{~m}, \mathbf{a} \phi$-value of 0.05 is obtained, indicating that internal mass transport is not limiting. Although some limitation will occur in particles having a lower conversion extent, we here neglect the influence of internal mass transport limitation.

Both the uncorrected and corrected value of $k_{\text {bed }}$ are now used to calculate the $\mathrm{SO}_{2}$-capture in the riser. This is done for a typical flue gas stream containing $0.2 \mathrm{vol} \% \mathrm{SO}_{2}$. We assume plugflow behaviour of the gas phase. Other assumptions and data are summarized in Table 3. In Fig. 18 the calculated $\mathrm{SO}_{2}$-removal at the outlet of the reactor is plotted as function of riser height. The influence of particleRTD is quite evident.

Table 3. Data uscd to calculate the $\mathrm{SO}_{2}$ removal in a circulating fluidized bed reactor

\begin{tabular}{ll}
\hline Bed porosity & $98 \%$ \\
Gas composition at inlet & 0.2 vol\% $\mathrm{SO}_{2}$ and 2 vol\% $\mathrm{O}_{2}$ in $\mathrm{N}_{2}$ \\
Gas flow pattern & Plug flow \\
Superficial gas velocity & $4.0 \mathrm{~m} \mathrm{~s}^{-1}$ \\
Solids flow rate & $10 \mathrm{~kg} \mathrm{~m}^{-2} \mathrm{~s}$ \\
Particle conversion per pass & $\leqslant 1 \% \%$ \\
Particle diameter & $1 \times 10^{-4} \mathrm{~m}$ \\
Maximum particle conversion & $50 \%$ \\
Average particle conversion/ & \\
utilization & $47.5 \% / 95 \%$ \\
$\beta$-factor & $0.31(\mathrm{or} \mathrm{1)}$ \\
Temperature & $700^{\circ} \mathrm{C}$ \\
Pressure & 1 atm \\
Reaction order in $\mathrm{SO}_{2}$ & 1 \\
Reaction order in $\mathrm{O}_{2}$ & 0 \\
Particle conversion behaviour & Product-layer diffusion limitation
\end{tabular}




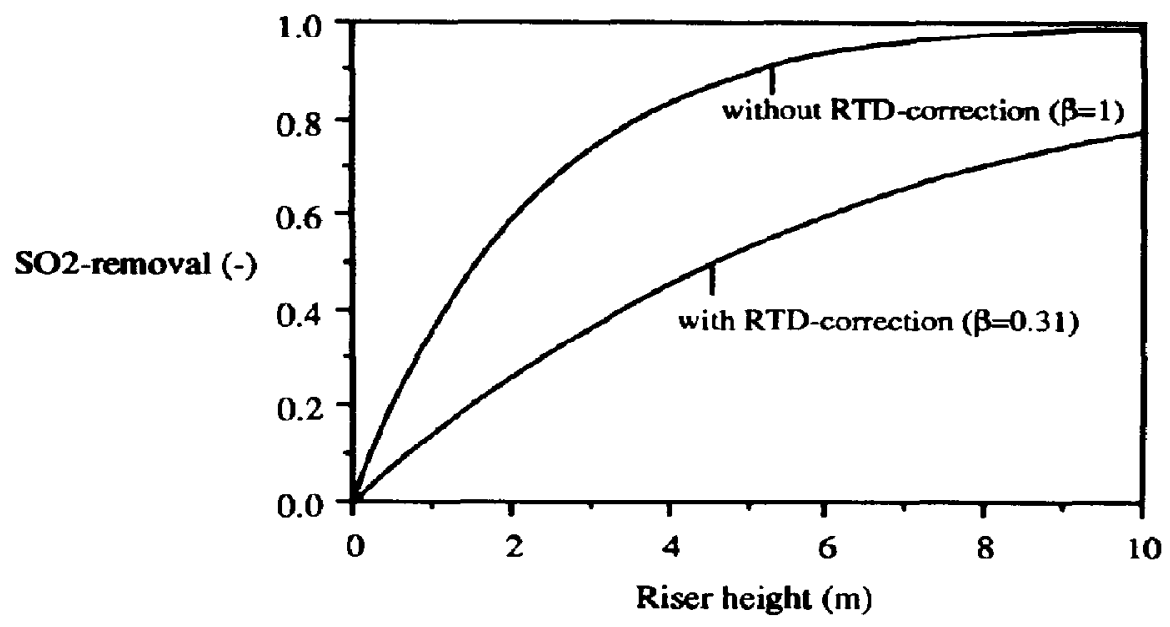

Fig. 18. Outlet concentration of $\mathrm{SO}_{2}$ vs static bed height for a circulating fluidized bed of precalcined limestone particles with $(\beta=0.31)$ and without $(\beta=1)$ correction for the influence of particle-RTD on reactivity.

\section{CONCIUISIONS}

The influence of particle-RTD on the average reactivity of particles undergoing a non-catalytic gas-solid reaction inside a continuously operated fluidized bed reactor has been evaluated. A $\boldsymbol{\beta}$-factor has been defined as the ratio of the actual reactivity in the reactor and the reactivity of a batch of particles that all have a conversion extent equal to the average conversion extent in the reactor. The $\beta$-factor concept was illustrated for nth order conversion behaviour of the particles and further elaborated for shrinking core conversion behaviour. In the cases of core reaction limitation and grain reaction limitation, particle-RTD was found to have a negative impact on reactivity, especially at high values of particle utilization. In case of product-layer diffusion limitation the influence appeared to be positive at low and moderate values of particle utilization and negative at high values of particle utilization. For each type of conversion behaviour a fit-function was derived by which $\beta$ can be calculated as function of the average particle conversion $\left(\bar{X}_{\text {Csstr }}\right)$, the maximum attainable particle conversion $\left(X_{\mathrm{max}}\right)$, and a new-defined expansion factor $(K)$ :

Core reaction limitation:

$$
\begin{aligned}
& \beta=1-\exp \left[-4.2\left(1-\frac{\bar{X}_{\text {CSSTR }}}{X_{\max }}\right)^{q}\right] \\
& q=1.5-0.9 \exp \left[-2\left(1-X_{\max }\right)^{0.85}\right] .
\end{aligned}
$$

Product-layer diffusion limitation:

$$
\begin{aligned}
\beta= & 1.65\left\{1-\exp \left[-\left(2+\frac{4.5}{K+1}\right)\right.\right. \\
& \left.\left.\times\left(1-\frac{\bar{X}_{\text {CSSTR }}}{X_{\max }}\right)^{q}\right]\right\}
\end{aligned}
$$

$$
\begin{array}{rlrl}
q= & 0.7+0.55\{1-\exp [(0.7 \log K-1.4) \\
& \left.\left.\times\left(1-X_{\max }\right)\right]\right\} & & \text { for } K>0 \\
q= & 0.7 & \text { for } K \leqslant 0 .
\end{array}
$$

Grain reaction limitation:

$$
\beta=1.3\left(1-\frac{\bar{X}_{\mathrm{CSSIR}}}{X_{\max }}\right)^{1.12-0.5 /(\mathrm{K}+1.6)}
$$

$$
\text { if } \beta \leqslant 1 \text { else } \beta=1 .
$$

The fit-function for grain reaction limitation is also applicable to reactions that are of zeroth order in the particles if a $K$-value of zero is inserted. However, this function should not be applied when $K$ is negative and $\beta$-values less that 0.1 are predicted.

In deriving the fit-functions, it was assumed that the only mass transfer resistance (if present) is located at the interface between the bubble and the emulsion phase. However, when the conversion rate of the particles is fully governed by external mass transport, the fit-function derived for grain reaction limitation can be applied. If internal mass transfer is limiting the conversion rate of porous particles, the fit-function derived for product-layer diffusion limitation is valid. A $K$-value of 0 should then be inserted.

The fit-functions can be easily incorporated in fluidized bed reactor models as was demonstrated for the capture of sulphur dioxide by precalcined limestone particles in a circulating fluidized bed reactor.

\footnotetext{
Acknowledgements-This investigation was supported by the Directorate-General XII of the European Communities and the Dutch organizations TNO-IMET and NOVEM B.V. We also acknowledge J. A. M. Kuipers for his assistance in the mathematical field.
} 


\section{NOTATION}

$C_{s}$

$C_{9}$

$C_{g}^{\prime}$

$C_{\mathrm{SO}_{2}, \text { bulk }}$

$C_{\mathrm{sO}_{2,3}}$

$d_{\boldsymbol{p}}$

$D_{s}$

$D_{\mathrm{SO}_{2}-\mathrm{N}_{2}}$

$D_{\mathrm{SO}_{2} \text {-ett }}$

$k_{\text {bed }}$

$k(X)$

$k_{c}$

$k_{g}$

K

$K_{\text {c }}$

$K_{g}$

$K_{p}$

$K_{\text {r }}$

$M$

$n$

$N_{0}$

$P$

$q$

$\boldsymbol{R}_{\text {BATch }}$

$R_{\text {Cssta }}$

$R_{\text {c }}$

$\boldsymbol{R}_{\boldsymbol{g}}$

$R_{0}$

$s$

Sh

$t$

$V_{\text {sol, reac }}$

$V_{\text {sol, prod }}$

$\boldsymbol{X}$

$\bar{X}_{\text {CSSTR }}$

$X_{\max }$ $\mathrm{mol} \mathrm{m}^{-3}$ $\mathrm{m}^{2} \mathrm{~s}^{-1}$ particles, $\mathrm{m}^{2} \mathrm{~s}^{-1}$ bed mass, $\mathrm{kg}$ sionless

time, $s$

$\mathrm{m}^{3} \mathrm{~mol}^{-1}$ concentration of the reactive species at the core surface, $\mathrm{mol} \mathrm{m}^{-2}$

concentration of the reactive species at the grain surface, mol $\mathrm{m}^{-2}$

concentration of the adsorbed gaseous reactant at the grain surface $\mathrm{mol} \mathrm{m}^{-2}$

volumetric $\mathrm{SO}_{2}$ concentration in gas bulk,

volumetric $\mathrm{SO}_{2}$ concentration in gas near particle surface, $\mathrm{mol} \mathrm{m}^{-3}$

diameter of reacting particle, $m$

diffusivity of the product layer, $\mathrm{m} \mathrm{s}^{-1}$ or

molecular diffusivity of $\mathrm{SO}_{2}$ in $\mathrm{N}_{2}, \mathrm{~m}^{2} \mathrm{~s}^{-1}$ effective diffusivity of $\mathrm{SO}_{2}$ inside reacting

volumetric first-order reaction rate constant in reactor, $s^{-1}$

volumetric first-order reaction rate constant in particle, $s^{-1}$

first-order reaction rate constant of the core surface reaction, $\mathrm{s}^{-1}$

first-order reaction rate constant of the grain surface reaction, $\mathrm{s}^{-1}$

expansion factor, dimensionless

overall reaction rate constant in the case of core reaction limitation, $\mathrm{s}^{-1}$

overall reaction rate constant in the case of grain reaction limitation, $s^{-1}$

overall reaction rate constant in the case of product-layer diffusion limitation, $s^{-1}$

overall reaction rate constant in the case of $n$th order conversion behaviour, $s^{-1}$

reaction order in particles, dimensionless initial concentration of solid reactant in the grains, mol $\mathrm{m}_{\mathrm{s}}^{-3}$

volume fraction of solid reactant in the grains, dimensionless

exponent in fit functions, dimensionless reactivity of a batch of particles having the same conversion extent, $\mathrm{mol} / \mathrm{m}_{\mathrm{p}}^{-3} \mathrm{~s}^{-1}$ reactivity inside a continuously operated fluidized bed reactor, mol $\mathrm{mp}_{\mathrm{p}}^{-3} \mathrm{~s}^{-1}$ radius of the unreacted core, $m$ radius of the (partly) converted grains, $m$ initial radius of the grains, $m$ product of $\tau$ and $K_{r}, K_{c}$ or $K_{\theta}$, dimen-

Sherwood number, dimensionless

molar volume of solid reactant,

volume of solid product produced per mol solid reactant, $\mathrm{m}^{3} \mathrm{~mol}^{-1}$

particle conversion, dimensionless

average conversion of the particles inside a CSSTR, dimensionless

maximum attainable conversion extent, dimensionless $y$

\section{Greek letters}

$\boldsymbol{\beta}$

$\varepsilon_{\text {bed }}$

$\varepsilon_{0}$

mensionless

$\phi \quad$ Thiele modulus, dimensionless

$\Phi_{m} \quad$ mass flowrate of particles, $\mathrm{kgs}^{-1}$

$\tau$ average residence time of the particles in the bed, $s$

$\tau_{\text {mix }} \quad$ time needed for complete mixing, $s$

$\tau_{\text {conv }} \quad$ time needed for complete conversion, $s$

$\psi \quad$ ratio between $K_{c}$ and $K_{p}$, dimensionless

\section{REFERENCES}

Abramowitz, M and Stegun, I. A. (eds.), 1972, Handbook of Mathematical Functions with Formulas, Graphs, and Mathematical Tables, 10th Edition Wiley, New York.

Borgwardt, R. H. and Bruce K. R., 1986, Effect of specific area on the reactivity of $\mathrm{CaO}$ with $\mathrm{SO}_{2}$. A.I.Ch.E. J. 32, $239-246$.

Cranfield, R. R., 1978, Solids mixing in fluidized beds of large particlcs. A.I.Ch.E. Symp. Ser. 74, 54-59.

Danforth, J. D. and Dix, J., 1971, Chemistry and kinetics of the thermal decomposition of zinc and magnesium oxalates, $J$. Am. Chem. Soc. 93, 6843-6846.

Dennis, J. S. and Hayhurst, A. N., 1987, The effect of $\mathrm{CO}_{2}$ on the kinetics and extent of calcination of limestone and dolomite particles in fluidized beds Engng Sci. 42 , 2361-2372.

Faltsi-Saravelou, O. and Vasalos, I. A., 1990, Simulation of a dry fluidized bed process for $\mathrm{SO}_{2}$ removal from flue gases. Ind. Engng Chem. Res. 29, 251-258.

Heesink, A. B. M., Prins, W. and Van Swaaij, W. P. M., 1993 A grain size distribution model for non-catalytic gas-solid reactions. Chem. Engng $J$. 53, 25-37.

Hogendoorn. J. A. Versteeg. G. F. and Van Swaaij, W. P. M 1993, Mass transfer accompanied by reversible chemical reactions in an inert porous sphere impregnated with a stagnant liquid. Chem. Engng Sci. 48, 2727-2740.

Kunii, D. and Levenspiel, O., 1991, Fluidization Engineering. Butterworth-Heinemann, Boston, Chap 18.

Lew, S., Sarofim, A. F. and Flytzani-Stephanopoulos, M. 1992, Modeling of the sulphidation of zinc-titanium oxide sorbents with hydrogen sulfide. A.I.CH.E. J. 38 1161-1169.

Nienow, A. W., Rowe, P. N. and Chiba, T., 1978, Mixing and segregation of a small proportion of large particles in gas fluidized beds of considerably smaller ones, A,I ChE Symp. Ser. 74, 176.

Park, J. Y. and Levenspiel, O., 1975, The crackling core model for the reaction of solid particles. Chem. Engng Sci. 30, $1207-1214$.

Rhodes, M. J., Zhou, S., Hirama, T. and Cheng, H., 1991 Effects of operating conditions on longitudinal solids mixing in a circulating fluidized bed riser. A.I.Ch.E. J. 37 , 1450-1458.

Rowe, P. N., 1973, Estimation of solids circulation rate in a bubbling fluidized bed. Chem. Engng Sci. 28, 979-980.

Sawaguchi, T., Inami, T., Kuroki, T. and Ikemura, T., 1990 Studies on thermal degradation of synthetic polymers XII Kinetic approach to intensity function concerning pyrolysis condition for polyethylene low polymer, Ind. Engng Chem. Process Des. Dev. 19, 174-179.

Schouten, J. C., 1988, Sulfur retention and particle motion during fluidized bed combustion of coal, Thesis, Technical University of Delft, Delft, Netherlands. 
Simons, G. A., Garman, A. R. and Boni, A. A., 1986, The kinetic rate of $\mathrm{SO}_{2}$-sorption by CaO. A.I.Ch.E. J. 33, 211-217.

Sitnai, O., 1981, Solids mixing in a fluidized bed with horizontal tubes; Ind. Engng Chem. Process Des. Dev. 20, 533-538.

Sohn, H. Y. and Szekely, J., 1972, A structural model for gas-solid reactions with a moving boundary-III. A general dimensionless representation of the irreversible reaction between a porous solid and a reactant gas. Chem. Engng Sci. 27, 763-778.

Sutherland, J. P. and Wong. K. Y.. 1964, Some segregation effects in packed-fluidized beds; Can. J. chem. Engng 42 , 163-167.

Thurner, F. and Mann, U., 1981, Kinetic investigation of wood pyrolysis. Ind. Engng Chem. Process Des. Dev. 20, 482-488.

Weast, R. C. (ed.), 1983, CRC Handbook of Chemistry and Physics, 64th Edition. CRC Press Bota Raton, Florida, pp. $200-217$.

Westerterp, K. R., Van Swaaij, W. P. M. and Beenackers, A. A. C. M., 1984a, Chemical Reactor Design and Operation. Wiley, Chichester, Chap. 5.

Westerterp, K. R., Van Swaaij, W. P. M. and Beenackers, A. A. C. M., 1984b, Chemical Reactor Design and Operation. Wiley, Chichester, p. 181.

Yagi, S. and Kunii, D., 1955, sth Symp. (Int.) on Combustion, Reinhold, New York, p. 231.

Yagi, S. and Kunii, D., 1961, fluidized-solids reactors with continuous solids feed--I. Residence time of particles in fluidized beds. Chem. Engng Sci. 16, 364-371.

\section{APPENDIX}

We will here examine the behaviour of $\beta$ at $\bar{X}_{\text {CsstR }}$-values close to zero in case of product-layer limitation. In the (irrealistic) case that product-layer diffusion is already rate determining during the initial stage of conversion, the following applies:

$$
\begin{aligned}
\lim _{X \downarrow 0}\left(\frac{\mathrm{d} X}{\mathrm{~d} t}\right) & =\lim _{X \downarrow 0}\left[\frac{3 K_{p}}{\frac{1}{(1-X)^{1 / 3}}-\frac{1}{(1+K X)^{1 / 3}}}\right] \\
& =\lim _{x \downarrow 0}\left[\frac{3 K_{p}}{f(X)}\right] .
\end{aligned}
$$

Taylor series cxpansion of the denominator in eq- (A1) yields

$$
\lim _{x \downarrow \rightarrow} f(X)=\frac{(K+1) X}{3}+O\left(X^{2}\right)
$$

with

$$
O\left(X^{2}\right)=\frac{2 X^{2}\left(1-K^{2}\right)}{9} \approx 0 \text { for } X \downarrow 0
$$

Thus, for small values of $X$ the following applies:

$$
\frac{\mathrm{d} X}{\mathrm{~d} t}=\frac{9 K_{p}}{(K+1) X} .
$$

Integration of eq. (A4) results in

$$
X(t)=\sqrt{\frac{18 K_{r} t}{K+1}} .
$$

Thus for small values of $\tau$ (and $X$ ), $X_{\text {CSSTR }}$ can be calculated according

$$
\bar{X}_{\mathrm{CSSTR}}=\int_{t=0}^{t=\infty}\left[\frac{1}{\tau} \exp \left(-\frac{t}{\tau}\right) \sqrt{\frac{18 K_{p} t}{K+1}} \mathrm{~d} t\right] .
$$

When substituting

$$
x=\sqrt{\frac{t}{\tau}}
$$

one obtains

$$
\vec{X}_{\text {CSSTR }}=2 \sqrt{\frac{18 K_{p} \tau}{K+1}} \int_{t=0}^{t=\infty}\left[x^{2} \exp \left(-x^{2}\right) \mathrm{d} x\right] .
$$

The latter integral is converging [see. e.g. Abramowitz and Stegun (1972)]

$$
\int_{t=0}^{t=\infty}\left[x^{2} \exp \left(-x^{2}\right) d x\right]=\frac{\sqrt{\pi}}{4} .
$$

Therefore,

$$
\bar{X}_{\mathrm{CSSTR}}=\frac{1}{2} \sqrt{\frac{18 K_{p} \pi \tau}{K+1}}
$$

$\beta$ is given by [eq. (9)]

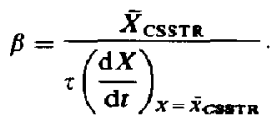

Inserting eqs (A4) and (A10) into (A11) finally yields

$$
\beta=\frac{\frac{1}{2} \sqrt{\frac{18 K_{p} \pi}{\tau(K+1)}}}{(K+1) \frac{1}{2} \sqrt{\frac{18 K_{p} \pi \tau}{K+1}}}=\frac{\pi}{2} .
$$

